\title{
Green is the new Black - A review of technologies for carboxylic acids recovery from black liquor
}

\begin{abstract}
Laura Reyes ${ }^{a}$, Clémence Nikitine ${ }^{* a}$, Léa Vilcocq ${ }^{* a}$ and Pascal Fongarland ${ }^{a}$
Carboxylic acids are one of the most important bulding blocks and feedstocks for fine chemicals, flavors and polymers, yet their production largely relays on petrochemical derivatives or processes that require large amounts of energy or chemicals. To ensure their long-term sustainable production it is necessary to explore different options of renewable feedstocks. An alternative solution is the recovery of carboxylic acids present in the black liquor. These compounds are formed as byproducts during the cooking stage in the Kraft pulping process, they are later burnt along with the other compounds present in black liquor to be transformed into energy. However, usually an energy surplus is generated due to the large amounts entering the unit, therefore their recovery and later use as renevewable feedstock could be considered as an advance in waste valorisation. Furthermore, the extraction of carboxylic acids from the black liquor can increase the pulp production, boosting the efficiency of the Kraft process. This review aims to examine the different technologies to recover carboxylic acids from black liquor as well as the challenges to be incorporated into the paper and pulp mills in order to become integrated forest biorefineries.
\end{abstract}

\section{Introduction}

The pulp and paper industry is one of the most important in the world, both in terms of volume produced and value generated. Paperboard and paper productions have increased over the recent years in order to meet the world consumption that has almost doubled since $1980 .{ }^{1}$ In 2014 a production of 404 million tons was achieved, and it was estimated that by the end of 2020 the global paper consumption would rise up to 500 million tons. The production distribution in 2018 was led by Asia-Pacific (196 million tons) followed by Europe (106 million tons), North America (82 million tons), Latin America (22 million tons) and Africa (4 million tons). The range of paper and cardboard products applications goes from newsprint and writing paper to packaging, domestic household and sanitary use. ${ }^{2}$ Among these products, the paper used for packaging represents more than half of worldwide consumption, followed by printing and writing with a quarter per volume of consumption and finally the sanitary and newsprint applications, as shown in Figure $1 .^{3}$

Pulp is the main component in the paper and paperboard manufacture. Industrially, this fibrous material can be obtained by mechanical and/or chemical treatment of lignocellulosic materials. The main difference between these two methods is based on the fact that the first one does not eliminate lignin, but rather separates the cellulose fibers by friction, while by means of the other; the material is deconstructed by dissolving lignin. The mechanical pulping process generally includes a pretreatment of the wood with steam before the recovery of the fiber by abrasive grinding or refining. In some cases, a treatment with aqueous sulfite solution may also be required; this would depend on the raw material. On the other hand, the chemical pulping treatment is based on chemical reactions at $130-170^{\circ} \mathrm{C}$ to soften and dissolve the lignin fraction of the raw material. This process usually precedes mechanical refining in order to achieve further fiber separation and recovery. In general terms, both processes are followed by washing, bleaching and purification operations that would be dictated by quality parameters of the enduse. $^{4}$

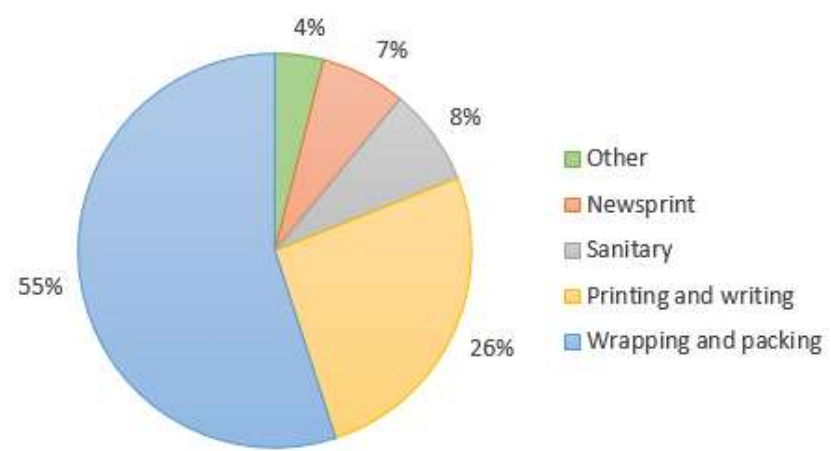

Figure 1. Global consumption distribution (adapted from Martin \& Haggith ${ }^{3}$ with authorization of Environmental Paper Network International).

At industrial level the principal chemical pulping treatments are Kraft, Sulfite and Soda processes, in order of industrial relevance. The first developed and industrialized chemical treatment was the Soda process. This technology is characterized by the use of a $\mathrm{NaOH}$ solution as a cooking agent; the process can be enhanced by the addition of anthraquinone as additive agent to decrease the carbohydrates degradation (Soda-AQ). Stronger pulping fibers can be obtained by the use of sulfites, in this case the wood chips are treated with a solution of a variety of sulfite/bisulfite salts, the calcium bisulfite $\left(\mathrm{Ca}\left(\mathrm{SO}_{3}\right)_{2}\right)$ being the most common one. In an attempt to improve the Soda process, sodium sulfate $\left(\mathrm{Na}_{2} \mathrm{SO}_{4}\right)$ was added in replacement of soda ash at the soda pulping recovery system. The change in the solution composition led to the formation of a cooking liquor, which included sodium sulfide $\left(\mathrm{Na}_{2} \mathrm{~S}\right)$ along with caustic soda. As a result, a darker but stronger and more resistant pulp was obtained. This efficient mix was patented and is currently known as the core of the Kraft process. ${ }^{5}$

\section{Black liquor from Kraft process}

Nowadays, the Kraft process is the dominant method within the chemical pulp extraction treatments for paper production. This manufacturing process includes a recycling loop, allowing to create 
strong durable paper from the extracted cellulose fibers but also to regenerate or use as energy source all the by-products. ${ }^{6}$

Paper production can be roughly described as a two-step process. First, a fibrous material is converted in pulp and following this stage the produced material is further processed into paper. An important part of the pulp comes from virgin fiber, but recycled paper is also considered as pulp source. The harvested wood, raw material, is carried to a sawmilling unit to obtain the wood chips that are treated in order to separate the fiber from the lignin fraction. This pulping process is achieved by chemical means in the digester. ${ }^{5}$ As mentioned before, the Kraft process involves the use of a hot aqueous solution of sodium hydroxide $(\mathrm{NaOH})$, sodium sulfide $\left(\mathrm{Na}_{2} \mathrm{~S}\right)$, industrially denoted as white liquor. The major role of this mixture is played by the hydrosulfide ion which accelerates the delignification as well as converting soda cooking from a nonselective to a selective delignifying process. ${ }^{4}$ The obtained pulp goes through a screening, washing, bleaching and refining process that will depend on the characteristics of the desired paper. ${ }^{5}$ The Figure 2 schematizes the general chemical pulping and papermaking process.

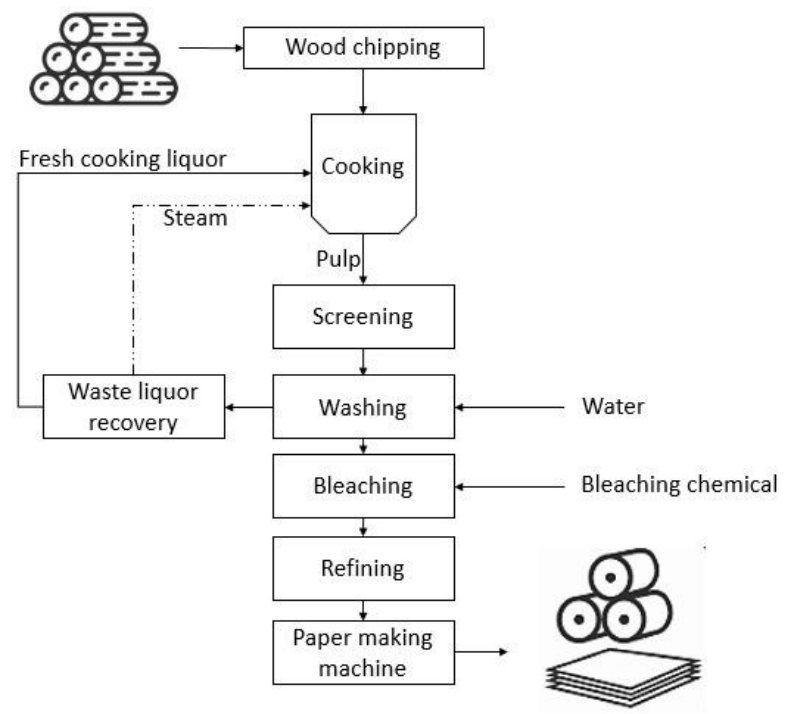

Figure 2. General Kraft pulping and papermaking process (original graphic inspired by $\left.\operatorname{Sixta}^{4}\right)$.

During the cooking stage carried out in the digester, the white liquor slowly adsorbs the degraded carbohydrates and lignin. Once the pulping process is completed, a waste stream is recovered, the black liquor (BL). This fraction contains the organic compounds of the raw material as well as the degraded and dissolved substances of the wood but also comprises an inorganic fraction mainly composed by cooking chemical residues. ${ }^{4}$ The lignin fraction is degraded to low molecular compounds containing phenolate, catecholate and carboxylate groups, whereas the carbohydrates degradation gives origin to carboxylic acids as hydroxy acids. ${ }^{5}$ It is estimated that 7 tons of weak black liquor are obtained per ton of produced pulp. This solution is generally valorized as energy. Weak black liquor contains $13-18 \%$ of dry solid content and is concentrated in an evaporator up to $65-70 \%$ in solids (heat content of $13.5-14.5 \mathrm{MJ} / \mathrm{kg}$ solid) before entering in the reboiler unit in order to be used as combustible. ${ }^{1}$

As result of the $\mathrm{BL}$ combustion in the recovery reboiler, a smelt is obtained ( $\mathrm{Na}_{2} \mathrm{~S}, \mathrm{Na}_{2} \mathrm{CO}_{3}$, and impurities). This product can be dissolved in water, forming the green liquor which can be further processed to produce white liquor. ${ }^{1}$ To do so, the green liquor is treated in a causticizing plant where it reacts with $\mathrm{CaO}$ and lime to transform the $\mathrm{Na}_{2} \mathrm{CO}_{3}$ into $\mathrm{NaOH}$. The precipitate formed during this reaction $\left(\mathrm{CaCO}_{3}\right)$ is washed and processed at high temperature to be regenerated to $\mathrm{CaO}$ thus continuing the use cycle. ${ }^{6}$ The Figure 3 illustrates the route followed by the white liquor from its use in the fiber line to its regeneration from the green liquor in the causticizing unit.

Figure 3. Kraft chemical recovery process ((original graphic inspired by Vakkilainnen and Tran ${ }^{6}$.

Typically, wood is the main source of pulp, this material is primarily composed by lignin, cellulose and hemicellulose. Considering the content of each component, wood can be classified as hardwood (e.g. Eucalyptus, Aspen, Birch) or softwood (e.g. Spruce, Pine, Larch). Even though that the cellulose (40-50\%) percentage is

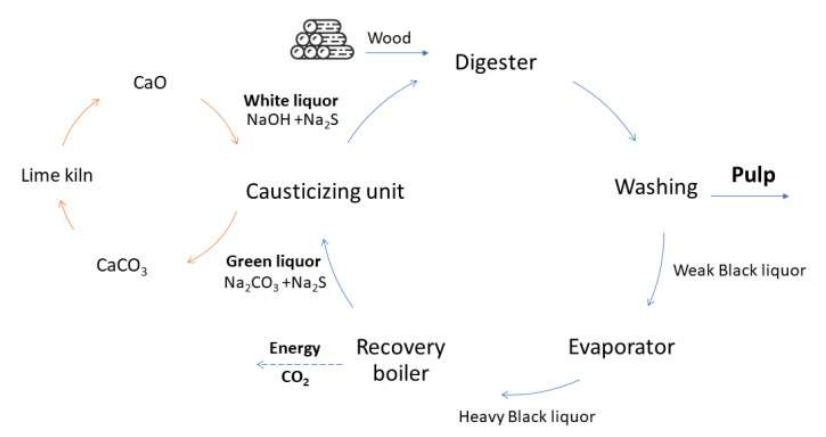

similar for both varieties, usually hardwoods have higher hemicellulose contents while the lignin fraction is much more important in softwoods. ${ }^{5}$ The Figure 4 shows the general softwood and hardwood compositions.

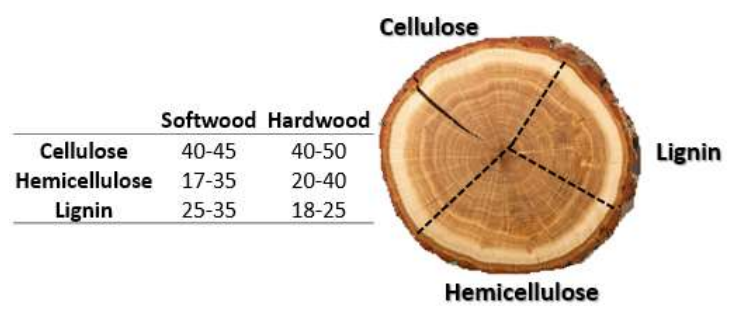

Figure 4 Softwood and Hardwood general composition (original graphic inspired by Bajpai $\left.^{7}\right)$.

The BL composition strongly depends on selected pulping process and raw material. Mainly organic substances as polysaccharides and lignin degradation products compose this complex solution. Along with the lignin fraction, carboxylic acids are the most important set of compounds in this mixture. Acetic, formic, saccharinic and hydroxy acids are the main components found in this fraction, as detailed below. ${ }^{7}$ The Table 1 shows a general BL composition result of either a Kraft or Soda-AQ process for two different kind of trees: Pine (softwood) and Birch (hardwood). It is illustrated that the composition of each type of wood has a strong influence on the characterization of BL. The Pine, softwood, presents a higher lignin content compared to the Birch, hardwood.

Table 1. BL characterization (percentage of the total dry matter). ${ }^{7}$ 


\begin{tabular}{ccccc}
\multirow{2}{*}{ Constituent } & \multicolumn{2}{c}{ Pine } & \multicolumn{2}{c}{ Birch } \\
& Kraft & Soda-AQ & Kraft & Soda-AQ \\
\hline Lignin & 43.2 & 36.8 & 31.8 & 32.6 \\
Aliphatic carboxylic acids & 30.7 & 31.7 & 35.2 & 34.8 \\
Other organics & 3.0 & 9.0 & 5.3 & 12.9 \\
Sodium content & 17.3 & 17.0 & 16.4 & 16.5 \\
\hline
\end{tabular}

By the other hand, the carboxylic acids that come from the hemicellulose fraction are more important in the Birch which also agrees with the original composition of the raw material.

As exposed before, the main valorization route of this product is its transformation into energy source for other parts of the production plant. ${ }^{7}$ More than 1.3 billion tons per year of weak BL are produced; from this, around 200 million tons of dry solids are burned. In this process, over 50 million tons of cooking liquor chemicals are recovered and at the same time, approximately 700 million tons of steam are produced. This energy production makes BL the fifth largest fuel used worldwide. ${ }^{6}$

Conventionally, black liquor is combusted in a recovery boiler to generate steam and electricity in a stream turbine combined heat power unit. Thus, a Kraft pulp mill is self-sufficient: all internal steam and electricity demand can be provided by recovering energy from dissolved lignin in the black liquor. Several studies have shown that the total energy balances of the mill from the electricity and heat demand of the processes has been positive, resulting in an excess of 0.5 to $1 \mathrm{MWh}$ per air-dry ton of pulp ${ }^{8-10}$. Moreover, due to the presence of high organic content from the dissolved lignin, black liquor represents a potential energy source estimated at 250-500 MW per mill that produces 1.7-1.8 tons of black liquor per ton of pulp. ${ }^{11}$

However, this energy recovery is very often in excess, so chemical recovery pathways are studied. Some approaches different to the valorization of $\mathrm{BL}$ as direct energy source have been studied, targeting the integration of the biorefinery concept to the pulp and paper industry. ${ }^{12}$ The principle of integrated forest biorefinery (IFBR) aims to produce others value-added products such polymers, carbon fibers, fuels, ethanol along with other building blocks. ${ }^{13}$ One of these alternatives technologies is the BL gasification, in which most of the organic content is converted into gas. The gas can be further transformed in biofuels or chemical compounds as dimethyl ether (DME). ${ }^{14,15}$

Another compound with prospects for market valorization is the lignin. This can be described as the compound that holds the wood fibers together. It has also become an interesting feedstock for valuable chemical products. Lignin is abundant in aromatics, thus can be exploited as an alternative for aromatic compounds that are usually obtained by petrochemical resources. ${ }^{16}$ This complex organic chemical is mostly burned to produce energy in pulp and paper mills but with the increasing research effort that has generated a better understanding of its chemical behavior, this compound can be valorized in lignosulfonates, dispersants, bioplastics, fuel among others. ${ }^{17}$ Kraft lignin valorization was already reviewed in several articles. ${ }^{17-19}$

Due to the increasing interest in some of the compounds (mainly acids) present in the $\mathrm{BL}$, some researchers have also targeted alternatives routes for their valorization. ${ }^{20-22}$ Carboxylic acids are the best-known type of organic acids. They are used on large scale in the chemical and food industry. The market share of organic acids was estimated c.a. 6 billion US\$ in 2015. ${ }^{23}$

Considering that the average heat value of the carboxylic acids fraction is $50 \%$ or less compared to lignin, the energy supply of paper mills will not be highly affected by their removal from BL. ${ }^{24}$ Thus, the partial recovery and subsequent valorization of these products gains more interest as a better alternative to their use as fuel. In particular, in Kraft process where a surplus energy is generated from the burning of $\mathrm{BL}$, this kind of recovery becomes more interesting and realistic. Furthermore, with the extraction of this fraction from the $\mathrm{BL}$ it is possible to boost the recovery capacity of the mill, which is of great interest due to the fact that the recovery boiler is usually the processes bottleneck and so increasing the pulp production. ${ }^{25}$

In general terms, aliphatic carboxylic acids present in $\mathrm{BL}$ can be classified in three main groups: volatile acids, hydroxy acids and isosaccharinic acids. The main carboxylic acids found in BL are shown in Figure 5. 
Volatile acids

Hydroxyacids<smiles>O=CO</smiles>

Formic acid<smiles>CC(O)C(=O)O</smiles>

Lactic acid<smiles>CC(=O)O</smiles>

Acetic acid<smiles>CCC(O)C(=O)O</smiles>

2-hydroxybutyric acid<smiles>O=C(O)C(O)CCCO</smiles>

2,5-dihydroxypentanoic acid

Isosaccharinic acids<smiles>O=C(O)[C@@](O)(CO)C[C@@H](O)CO</smiles>

$\alpha$-glucoisosaccharinic acid<smiles>O=C(O)C(O)(CO)C[C@@H](O)CO</smiles>

$\beta$ - glucoisosaccharinic acid<smiles>O=C(O)C(O)(CO)CCO</smiles>

Xyloisosaccharinic acid

Figure 5. Main carboxylic acids found in BL.
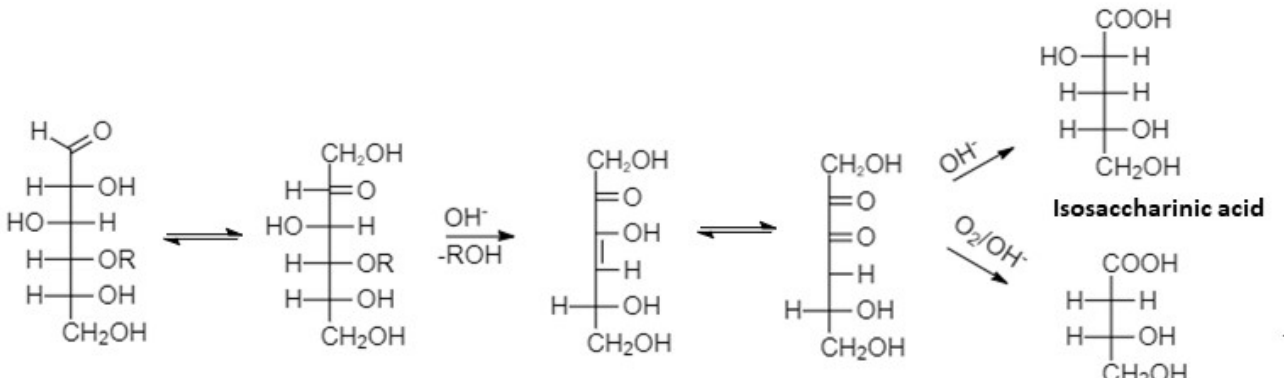

$\mathrm{COOH}$

$\mathrm{CH}_{2} \mathrm{OH}$

3,4-Dihydroxybutyric acid

Glycolic acid

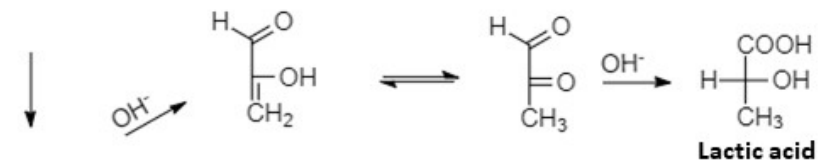

$\mathrm{CH}_{2} \mathrm{OH}$
$=\mathrm{O}$
$\mathrm{CH}_{2} \mathrm{OH}$

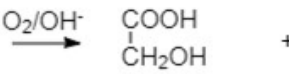

$\mathrm{HCOOH}$

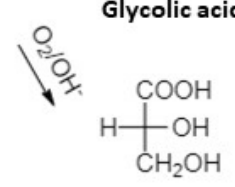

Formic acid

Glyceric acic 
Volatile acids as formic and acetic acid are formed by the deacetylation of hemicellulose acetyl groups during the initial delignification phase whereas the formic acid is formed evenly all along the peeling reaction. ${ }^{25}$ By one hand, regarding the main hydroxy acids, 2-hydroxybutanoic and xylo-isosaccharinic acids are formed from xylans (pentosan) whereas the $\alpha / \beta$-gluco-isosaccharinic acids are produced by hexosans like galactoglucomannan and cellulose. On the other hand, glycolic, lactic, 2,5-dihydroxypentanoic acid and 3-deoxypentoic are formed by all the polysaccharides constituents present in the feedstock. ${ }^{26}$

Generally speaking, these acids along with the acetic and formic acids are the most important compounds in BL carboxylic acid fraction. ${ }^{26}$ These acids are mainly produced through the alkaline Peeling reaction. At temperatures higher than $80^{\circ} \mathrm{C}$ and in alkaline $\mathrm{pH}$ carbohydrates are degraded by the reducing end group. ${ }^{27}$

The products of this reaction (peeled-off units) are transformed into hydroxy carboxylic acids. This reaction is responsible for the greater loss of carbohydrates during alkaline pulping. ${ }^{27}$ The reaction starts by the isomerization of the aldose reducing terminal into a ketosis, followed by the tearing-off of a proton by the $\mathrm{OH}^{-}$, allowing a $\beta$-elimination that releases a new reducing aldose and a monosaccharide which is further transformed into an isosaccharinic acid. The Peeling reaction competes directly with the stopping reaction, that avoids the complete depolymerization which transforms the reducing end of cellulose into a carboxylic acid not sensible to alkaline Peeling reaction. ${ }^{28}$ Figure 6 illustrates the peeling reactions of polysaccharides (glucomannans and cellulose).

The Table 2 summarizes some of the BL acids compositions found in the literature. Most of these studies agreed in the characterization of the solution from a qualitative point of view, but regarding the quantities the characterization results differ. Formic and Acetic acids are the representative ones among the volatile acids. The most common hydroxy acids reported in BL bibliography are Glycolic, Lactic, 2,5-Dihydroxypentanoic and 2-Hydroxybutanoic. Finally, regarding the isosaccharinic acids, the most important exponents are $\alpha / \beta$-gluco-isosaccharinic and xylo-isosaccharinic.

The principal hemicelluloses forms found in softwood and hardwood are arabino-4-0-methylglucoronoxylan and 0-Acetyl-4-Omethyl glucuronoxylan, respectively. ${ }^{29}$ Contrary to hardwood xylans, softwood xylans are not acetylated. The hydrolysis of acetate groups on the hemicellulose chains yields acetic acid. ${ }^{1}$

Therefore, it explains the correlation of the high content of acetic acid in hardwood BL from alkaline pulping. Softwoods hemicelluloses usually are abundant in hexoses whereas hardwood generally composed by large amounts of pentoses. ${ }^{1}$ Thus, this explains the more important presence of $\alpha / \beta$-gluco-isosaccharinic acids in softwoods than in hardwood BL. In contrast, xylo-isosaccharinic and hydroxybutanoic acids are generally found in higher quantities in hardwood liquors. 
Table 2. Carboxylic acids composition in BL (values in g. $\mathrm{L}^{-1}$ ).

\begin{tabular}{|c|c|c|c|c|c|c|c|c|c|c|c|c|c|c|c|c|}
\hline \multirow{3}{*}{$\begin{array}{c}\text { Reference } \\
\text { Pulping process } \\
\text { Wood* }\end{array}$} & \multicolumn{2}{|c|}{30} & \multirow{3}{*}{$\begin{array}{c}1 \\
\text { Soda AQ } \\
\text { Pine }\end{array}$} & \multicolumn{4}{|c|}{$7 \$$} & \multicolumn{3}{|c|}{32} & \multicolumn{3}{|c|}{33} & \multirow{3}{*}{$\begin{array}{c}34 \\
\text { Kraft } \\
\text { sw-Hw } \\
\end{array}$} & \multirow{2}{*}{\multicolumn{2}{|c|}{$\begin{array}{c}35 \\
\text { Soda }\end{array}$}} \\
\hline & Kraft & Kraft AQ & & $\mathrm{Kraft}^{\text {s }}$ & SodaAQ & $\mathrm{Kraft}^{\mathrm{s}}$ & SodaAQ & & Kraft & & & Kraft & & & & \\
\hline & \multicolumn{2}{|c|}{ Birch } & & \multicolumn{2}{|c|}{ Pine $^{\$}$} & \multicolumn{2}{|c|}{ Birch $^{\$}$} & pine & Birch & Eucalypt & Sw & Birch & Aspen & & $\mathrm{Hw}$ & Sw \\
\hline Volatile acids & 7.6 & 7.6 & 18.39 & 11.76 & 9.61 & 17.32 & 17.71 & - & - & - & - & - & - & 16.7 & 19.1 & 9.8 \\
\hline Formic & 2.3 & 2.3 & 9.44 & 7.06 & 4.91 & 5.46 & 5.12 & - & - & - & - & - & - & 10 & 5.4 & 5.4 \\
\hline Acetic & 5.3 & 5.3 & 8.95 & 4.70 & 4.69 & 11.86 & 12.60 & - & - & - & - & - & - & 6.7 & 13.7 & 4.4 \\
\hline Main hydroxy acids & 14.12 & 11.18 & 20.78 & 8.47 & 9.22 & 8.27 & 7.13 & 10.89 & 14.82 & 9.29 & 8.04 & 8.59 & 7.28 & 10.2 & 9.1 & 9.6 \\
\hline Glycolic & 2.31 & 2.6 & 5.33 & 2.36 & 2.19 & 1.09 & 1.39 & 2.54 & 2.31 & 1.99 & 1.32 & 0.98 & 0.83 & 2.8 & 1.2 & 2.8 \\
\hline Lactic & 2.83 & 2.81 & 6.74 & 2.73 & 3.04 & 2.11 & 1.95 & 4.2 & 3.83 & 2.65 & 3.27 & 2.11 & 2.09 & 5.1 & 2.8 & 4.2 \\
\hline Hydroxubutanoic & - & - & - & 0.86 & 0.89 & 4.01 & 2.54 & - & - & - & - & - & - & - & - & - \\
\hline 4-Hydroxybutanoic & 0.1 & 0.1 & - & - & - & - & - & 0.19 & 0.1 & 0.08 & 0.13 & 0.09 & 0.11 & - & - & - \\
\hline 2-Hydroxibutanoic & 6.82 & 3.48 & 1.78 & - & - & - & - & 1.04 & 6.82 & 2.95 & 0.99 & 4.51 & 3.35 & 1.2 & 4 & 1.3 \\
\hline Dideoxyopentanoic & 1.18 & 0.84 & 3.80 & 2.03 & 1.71 & 0.74 & 0.59 & 1.46 & 0.88 & 0.81 & 2.33 & 0.9 & 0.9 & 1.1 & 1.1 & 1.3 \\
\hline Deoxypentanoic & 0.88 & 1.35 & 3.13 & 0.49 & 1.39 & 0.32 & 0.66 & 1.46 & 0.88 & 0.81 & - & & & & & \\
\hline Others & 2.39 & 4.04 & 1.9616 & 0.55 & 1.11 & 0.46 & 0.90 & 1.83 & 1.91 & 1.64 & 0.29 & 0.42 & 0.15 & 0 & 0.5 & 0.5 \\
\hline Propionic & - & - & - & - & - & - & - & - & - & - & - & - & - & - & - & - \\
\hline Malic acid & 0.27 & 0.24 & - & - & - & - & - & 0.16 & 0.27 & 0.19 & 0.13 & 0.22 & - & - & - & - \\
\hline Oxalic & 0.17 & 0.98 & - & - & - & - & - & 0.13 & 0.17 & 0.42 & - & - & - & - & 0.5 & 0.5 \\
\hline Succinic & 0.22 & 0.18 & - & - & - & - & - & 0.22 & 0.22 & 0.33 & 0.16 & 0.2 & 0.15 & - & - & - \\
\hline Deoxytetronic & 0.69 & 1.53 & 0.80 & 0.06 & 0.32 & 0.32 & 0.70 & 1.16 & 0.69 & 0.41 & - & - & - & - & - & - \\
\hline Dideoxyhexonic & 0.86 & 0.98 & 0.37 & 0.21 & 0.35 & 0.07 & 0.14 & 0.16 & 0.56 & 0.29 & - & - & - & - & - & - \\
\hline Anhydroglucoisosaccharinic & 0.18 & 0.13 & 0.80 & 0.28 & 0.44 & 0.07 & 0.07 & & & & - & - & - & - & - & - \\
\hline Isosaccharinic acids & 7.87 & 6.27 & 13.49 & 6.57 & 7.64 & 5.53 & 4.94 & 9.45 & 7.87 & 5.38 & 7.52 & 6.14 & 6.74 & 10 & 10.5 & 19.4 \\
\hline Xylo-isosaccharinic & 3.76 & 3.14 & 0.92 & 0.28 & 0.35 & 3.06 & 2.58 & 0.48 & 3.76 & 1.9 & 0.59 & 3.31 & 3.19 & 4.2 & 3.2 & 3.7 \\
\hline Gluco-isosaccharinic & - & - & - & 6.29 & 7.29 & 2.46 & 2.37 & 8.97 & 4.11 & 3.48 & - & - & - & 5.8 & 7.3 & 15.7 \\
\hline alfa & 0.99 & 0.95 & 3.68 & - & - & - & - & - & - & - & 2.01 & 0.79 & 0.98 & - & - & - \\
\hline beta & 3.12 & 2.18 & 8.89 & - & - & - & - & - & - & - & 4.92 & 2.04 & 2.57 & - & - & - \\
\hline
\end{tabular}




\begin{tabular}{|c|c|c|c|c|c|c|c|c|c|c|c|c|c|c|c|c|c|c|}
\hline \multirow{3}{*}{$\begin{array}{c}\text { Reference } \\
\begin{array}{c}\text { Pulping process } \\
\text { Wood* }\end{array} \\
\end{array}$} & \multirow{2}{*}{\multicolumn{4}{|c|}{$\begin{array}{c}36 \\
\text { Soda }\end{array}$}} & \multirow{3}{*}{$\begin{array}{c}37 \\
\text { Kraft } \\
\mathrm{Hw} \\
\end{array}$} & \multirow{2}{*}{\multicolumn{2}{|c|}{$\begin{array}{c}38 \\
\text { Kraft }\end{array}$}} & \multicolumn{2}{|c|}{39} & \multirow{3}{*}{$\begin{array}{c}40 \\
\begin{array}{c}\text { Soda AQ } \\
\text { Birch }\end{array} \\
\end{array}$} & \multirow{3}{*}{$\begin{array}{c}41 \\
\text { Kraft }\end{array}$} & \multirow{2}{*}{\multicolumn{2}{|c|}{$\begin{array}{c}42 \\
\text { Soda }\end{array}$}} & \multicolumn{2}{|c|}{43} & \multirow{3}{*}{$\begin{array}{c}21 \\
\text { Kraft } \\
\text { Eucalyptus } \\
\end{array}$} & \multicolumn{2}{|r|}{44} \\
\hline & & & & & & & & \multirow{2}{*}{$\begin{array}{c}\text { Soda AQ } \\
\text { Spruce }\end{array}$} & \multirow{2}{*}{$\begin{array}{c}\text { Kraft } \\
\text { Spruce }\end{array}$} & & & & & Soda & Kraft & & Soda & Kraft \\
\hline & $\mathrm{Hw}$ & Sw & $\mathrm{Hw}$ & Sw & & $\mathrm{Hw}$ & Sw & & & & & $\mathrm{Hw}$ & $\mathrm{Hw}$ & $\mathrm{H}$ & & & & $\mathrm{Hw}$ \\
\hline Volatile acids & 15 & 7.66 & 52.46 & 21.47 & 23.51 & 10 & 18 & 8.3 & 9.4 & 23.5 & 1.67 & 12.4 & 19.88 & 23.83 & 23.36 & 10.5 & 9.81 & 23.82 \\
\hline Formic & 3.5 & 3.85 & 13 & 10.7 & 6.2 & 5 & 12 & 4.5 & 5.3 & 6.2 & 0.36 & 4.45 & 7.74 & 7.42 & 7.07 & 2.3 & 3.82 & 15.07 \\
\hline Acetic & 11.5 & 3.81 & 39.46 & 10.77 & 17.3 & 5 & 6 & 3.8 & 4.1 & 17.3 & 1.31 & 7.95 & 12.14 & 16.41 & 16.29 & 8.2 & 5.99 & 8.75 \\
\hline Main hydroxy acids & 7.08 & 6.95 & 26.71 & 18.11 & 10.2 & 3 & 7 & 7.2 & 5.2 & 10.3 & 0.6 & 11.07 & 32.25 & 8.43 & 20.05 & 9 & 8.16 & 8.16 \\
\hline Glycolic & 1.02 & 1.37 & 3.26 & 3.75 & 2.0 & 1 & 3 & 2.8 & 1.1 & 2 & & 1.75 & 4.21 & 2.05 & 1.32 & & 2.08 & 3.83 \\
\hline Lactic & 1.98 & 3.54 & 7.05 & 9.22 & 2.3 & 2 & 4 & 3.5 & 3.2 & 2.3 & 0.6 & 3.78 & 12.33 & 6.38 & 5.43 & 9 & 6.08 & 4.33 \\
\hline Hydroxubutanoic & - & - & - & - & - & - & - & - & - & - & - & - & - & - & - & - & - & - \\
\hline 4-Hydroxybutanoic & 4.08 & 1.12 & 16.4 & 2.89 & - & - & - & - & - & - & - & - & - & - & - & - & - & - \\
\hline 2-Hydroxibutanoic & - & - & - & - & 3.2 & - & - & 0.9 & 0.9 & 3.2 & - & 4.56 & 11.46 & - & 5.49 & - & - & - \\
\hline Dideoxyopentonic & - & 0.92 & - & 2.25 & 1.3 & - & - & - & - & 1.3 & - & 0.98 & 4.25 & - & 7.81 & - & - & - \\
\hline Deoxypentonic & - & - & - & - & 1.5 & - & - & - & - & 1.5 & - & - & - & - & - & - & - & - \\
\hline Others & - & - & 1.41 & 1.08 & - & - & - & - & - & - & - & - & - & 13.34 & & 67 & 11.84 & 5.89 \\
\hline Propionic & - & - & - & - & - & - & - & - & - & - & - & - & - & - & & 4.2 & - & - \\
\hline Malic acid & - & - & - & - & - & - & - & - & - & - & - & - & - & 6.17 & & 0.6 & 5.65 & 2.59 \\
\hline Oxalic & - & - & 1.41 & 1.08 & - & - & - & - & - & - & - & - & - & - & & 62.2 & - & - \\
\hline Succinic & - & - & - & - & - & - & - & - & - & - & - & - & - & 3.19 & & - & 2.1 & 2.25 \\
\hline Deoxytetronic & - & - & - & - & - & - & - & - & - & - & - & - & - & - & & - & - & - \\
\hline Dideoxyhexonic & - & - & - & - & - & - & - & - & - & - & - & - & - & 3.98 & & - & 4.09 & 1.05 \\
\hline $\begin{array}{c}\text { Anhydro- } \\
\text { glucoisosaccharinic }\end{array}$ & - & - & - & - & - & - & - & - & - & - & - & - & - & & & - & - & - \\
\hline Isosaccharinic acids & 6.47 & 11.78 & 23.2 & 31.98 & 5.8995 & 4 & 16 & 8.7 & 10.8 & 5.9 & - & 10.64 & 33.3 & 12.23 & 11.8 & - & 12.33 & 9.46 \\
\hline Xylo-isosaccharinic & 3.5 & 2.72 & 12.7 & 7.42 & 3.0 & 1 & 5 & 0.8 & 0.7 & 3 & - & 2.66 & 8.29 & - & 2.9 & - & - & - \\
\hline Gluco-isosaccharinic & 2.97 & 9.06 & 10.5 & 24.56 & 2.9 & 3 & 11 & 7.9 & 10.1 & 2.9 & - & 7.98 & 25.01 & 12.23 & 8.9 & - & 12.33 & 9.46 \\
\hline alfa & - & - & - & - & - & - & - & - & - & - & - & - & - & - & - & - & - & - \\
\hline beta & - & - & - & - & - & - & - & - & - & - & - & - & - & - & - & - & - & - \\
\hline
\end{tabular}

$\$$ values in percentage on dry matter basis. 


\section{Properties of the main carboxylic acids present in black liquor}

\subsection{Volatile acids}

Acetic and formic acid form the volatile acids group present in BL. Table 3 presents some of the main properties as well as the potential production and market value from BL.

Table 3. .Properties of volatile acids presents in BL.

\begin{tabular}{|c|c|c|c|}
\hline Properties & & Formic & Acetic \\
\hline Chemical formula & & $\mathrm{CH}_{2} \mathrm{O}_{2}$ & $\mathrm{C}_{2} \mathrm{H}_{4} \mathrm{O}_{2}$ \\
\hline Molecular weight & [g/mol] & 46.03 & 60.05 \\
\hline Density & {$\left[\mathrm{g} / \mathrm{cm}^{3}\right]$} & 1.154 & 1.068 \\
\hline Boiling point & {$\left[{ }^{\circ} \mathrm{C}\right]$} & 100.6 & 117.1 \\
\hline Vapor pressure & {$[\mathrm{kPa}]$} & 4.87 & 1.85 \\
\hline Enthalpy of vaporization & {$[\mathrm{kJ} / \mathrm{mol}]$} & 22.69 & 23.7 \\
\hline Current production & [kt/year] & $1015^{45}$ & $13000^{46}$ \\
\hline Market price & {$[\mathrm{USD} / \mathrm{t}]$} & $600-700^{\S}$ & $700-750^{\#}$ \\
\hline $\begin{array}{l}\text { Production potential from } \\
\qquad \mathrm{BL}^{* *}\end{array}$ & [kt/year] & 12000 & 17000 \\
\hline Market potential from $B L^{* * *}$ & [M\$] & 7205 & 12456 \\
\hline
\end{tabular}

*Predicted properties at $101.325 \mathrm{kPa}$ and $20^{\circ} \mathrm{C}$

**Calculated from the annual production of $\mathrm{BL}$ (equivalent to chemical wood pulp production, 156 million tons in 2016, FAOSTAT source) and an average acid content in $\mathrm{BL}$.

***Calculated from the potential of production and current market price §source: http://chemplan.biz, 2014 value

\#source: ICIS pricing 2014

3.1.1. Formic acid. The methanoic acid, most known as formic acid is considered as an important intermediate in chemical synthesis. This acid is naturally produced by ants, bees and some plants. Concerning its miscibility, this compound is partially miscible in hydrocarbons mixtures but entirely miscible in water and some others polar solvents as alcohols, acetone and ether. ${ }^{47}$

The global production in 2016 was about 1015 kt and a production of $1217 \mathrm{kt}$ was predicted for 2022. Industrially, it is produced either by acidolysis of formate salts or hydrolysis of methyl formate ( $80 \%$ of the worldwide production). The most common technology to produce the latter one is the base-catalyzed methanol carbonylation. ${ }^{45}$ Some other mechanisms, as the use of carbon dioxide, have been studied as alternatives for formic acid manufacture. ${ }^{46}$ Due to its aldehydic nature, acidity and reducing properties, formic acid is used in a large variety of industries. Textile, leather and tanning, animal feed preservation, pharmaceutical and food additives are some examples of industrial applications. ${ }^{47} \mathrm{It}$ also has a great potential as an alternative combustible for portable fuel cell, as have been demonstrated by the development of direct formic acid fuel cells (DFAFC). ${ }^{50-52}$

Besides from these direct applications, formic acid can also be used to synthesize other compounds. Esters, formamides, salts and performic acid are the most important products among its derivatives. The highly acidic character of this acid makes inessential the use of mineral catalyst in simple esterification with primary, secondary and tertiary alcohols. In comparison with the two-carbon carboxylic acid (acetic acid), the esterification reaction of primary and secondary alcohols are 15000-20000 times faster in pure formic acid. ${ }^{45}$ Formate esters are easy to hydrolyze to their original corresponding alcohol and corresponding acid. These products are flammable, volatile and barely soluble in water. ${ }^{53,54}$

Regarding salts production, formic acid can be used to synthetize sodium, potassium, ammonium, calcium, aluminium, and cesium formates. These salts are used as antifreeze, DeNOx products, supplement in feed, textile and pharmaceutic and drilling fluid. ${ }^{45}$

3.1.2. Acetic acid. Acetic acid is generally used as solvent, food preservative or as intermediate for a large diversity of commercial chemicals. This acid is highly miscible in water, usually forming vinegar $(4 \% \mathrm{v} / \mathrm{v})$, but is also miscible in other substances as acetone, ethanol, benzene and ether. ${ }^{55}$ The global acetic acid demand for 2015 was $13 \mathrm{Mt}$ and it was forecasted that its production would reach the $18 \mathrm{Mt}$ by 2020. It can be industrially produced by bacterial fermentation; however, this route is preferential for applications in food as vinegar. The main synthetic routes are methanol carbonylation ( $75 \%$ of the total production) and acetaldehyde oxidation. ${ }^{46}$

The most important acetic acid end uses are the manufacture of vinyl acetate, monochloroacetic acid, acetic anhydride and acetate esters. The latter ones are produced by the acid catalyzed reaction of the acid with an alcohol (ethanol, methanol, propanol and butanol), producing their respective acetate. The properties of these products are related to the original alcohol, thus ranging the applications from solvents, coatings, gums and resins. ${ }^{37}$

\subsection{Hydroxy acids}

The major non-volatile carboxylic acids fraction includes diverse hydroxy mono and dicarboxylic along with small quantities of nonhydroxylated acids. Numerous studies targeting the hydroxy acid fraction from alkaline pulping liquors had sustained their presence with almost a hundred identified compounds. ${ }^{32}$ Table 4 summarizes the main hydroxy acids properties as well as potential production and market value from their production from $\mathrm{BL}$. 


\begin{tabular}{|c|c|c|c|c|c|}
\hline Properties & & Lactic & Glycolic & 2,5 dihydroxypentanoic & 2-Hydroxybutyric \\
\hline Chemical formula & & $\mathrm{C}_{3} \mathrm{H}_{6} \mathrm{O}_{3}$ & $\mathrm{C}_{2} \mathrm{H}_{4} \mathrm{O}_{3}$ & $\mathrm{C}_{5} \mathrm{H}_{10} \mathrm{O}_{4}$ & $\mathrm{C}_{4} \mathrm{H}_{8} \mathrm{O}_{3}$ \\
\hline Molecular weight & {$[\mathrm{g} / \mathrm{mol}]$} & 90.08 & 76.05 & 134.13 & 104.1 \\
\hline Density & {$\left[\mathrm{g} / \mathrm{cm}^{3}\right]$} & 1.276 & 1.416 & 1.32 & 1.195 \\
\hline Enthalpy of vaporization & {$[\mathrm{kJ} / \mathrm{mol}]$} & 53.96 & 58.47 & 67.04 & 55.22 \\
\hline Current production & [kt/year] & $750^{56}$ & $40^{62}$ & - & - \\
\hline Market price & {$[\mathrm{USD} / \mathrm{t}]$} & $18000^{\S}$ & $2300^{\#}$ & - & - \\
\hline Production potential from $B L^{* *}$ & [kt/year] & 6930 & 3990 & 3340 & 5360 \\
\hline Market potential from $B L^{* * *}$ & [M\$] & 15940 & 71930 & - & - \\
\hline
\end{tabular}

*Predicted properties at $101.325 \mathrm{KPa}$ and $20^{\circ} \mathrm{C}$

**Calculated from the annual production of $\mathrm{BL}$ and an average acid content in BL.

***Calculated from the potential of production and current market price.

§source: NNFC 2011

\#source: Grand View Research 2016

3.2.1. Lactic acid. The global market for lactic acid was 750 kilo tons and is projected to reach 1844 kilo tons by $2022 .{ }^{56}$ Lactic acid has gained attention for being the monomer for biodegradable polylactic acid (PLA) manufacturing. It can be produced industrially by chemical synthesis but the carbohydrate fermentation process is the main way to obtain it. 57,58 This compound is completely soluble in ethanol, water, diethyl ether along with other organic solvents miscible in water. ${ }^{59}$

The three main applications of lactic acid and its derivatives, salts and esters, are: polymers (PLA), food and commodities. Lactate salts are mainly used as preservatives and acidulants whereas the lactate esters found their application as solvents being biodegradable, noncorrosive, non-carcinogenic and non-ozone-depleting their most interesting features. ${ }^{60}$ Lactates produced by lower alcohols are rather easy to carry out by direct reaction, an increase in the yield can be achieved by water constant removal with azeotropic distillation. ${ }^{59}$

3.2.2. Glycolic acid. It can be produced by diverse synthesis routes. Industrially, the acid-catalyzed formaldehyde carbonylation is the predominant fabrication process due to low associated costs. ${ }^{61}$

It can also be produced by enzymatic biochemical process by ethylene glycol oxidation and glycolonitrile hydrolysis. ${ }^{62,63}$ In 2011 a production of $40 \mathrm{kt}$ per year was achieved and it was forecasted to double by the end of the decade. ${ }^{64}$ Glycolic acid is soluble in methanol, ethanol, acetone, ethyl acetate and water. Among its direct applications, it is used in the food industry as a flavoring and preservative agent. Due to its excellent adsorption on the skin, it has a variety of applications in skin care, it is generally used by dermatologists in chemical peeling. ${ }^{64}$

This compound is an important intermediary in organic synthesis in a reaction range such as oxy-reduction, esterification and polymerization. It is used as monomer in polyglycolic acid and other biocompatible copolymers. The esters formed by this acid as methyl glycolate and ethyl glycolate are employed as resins solvents, n-butyl glycolate as a much more commercial relevance and its applications are mainly as varnish, resins and oil-based paints additive. ${ }^{65}$

3.2.3. Hydroxybutyric Acids. 2-Hydroxibutanoic, 3-hydroxybutanoic and 4-hydroxybutanoic form the hydroxybutyric acids. These acids are soluble in ethanol, water, diethyl ether, and some other organic solvents. Hydroxybutyric acids current applications are limited to niche markets such as skincare. ${ }^{66}$ Whereas the related lactones can be used as starting materials in organic synthesis as well as solvents and flavors. Poly-hydroxybutyric acids (PHB) can be synthesized and used as biodegradable polymers in medical applications. ${ }^{64}$ Specifically, 4-hydroxybutanoic acid has been used in pharmacology as a pain killer or anesthetic. ${ }^{64}$

From these acids, 2-hydroxybutanoic acid is the most abundant in Kraft BL. It is formed by the isomerization of the xylan reducing end group to a pentulose, which goes later to a beta-elimination reaction. The reaction path can be depressed by the $A Q$ addition to the cooking liquors. ${ }^{30}$

3.2.4. Dihydroxy acids. At the moment, there is no industrial production or market for 2,5-dihydroxy acid. Nevertheless, other polyhydroxy acids such as glyceric acid or glucaric acid have been identified as interesting bio-based building blocks for several applications, e.g. for polymers or commodities synthesis. ${ }^{67}$

\subsection{Isosaccharinic acids}

Millions of tons of saccharinic acids are produced each year by the alkaline pulping process in the paper mills. The partial depolymerization caused by the peeling reaction produced in alkaline conditions on cellulosic and hemicellulosic materials generates saccharinic acids. $\alpha / \beta$-gluco-isosaccharinic acids are derived from cellulose and various polysaccharides such as mannans and galactans, while xylo-isosaccharinic acid comes from the arabinoxylan fraction of the plant cell wall. ${ }^{68}$ Table 5 presents the main properties and potential production of isosaccharinic acids from BL.

One reason on the growing interest in these acids is their vast availability thus synthesis routes can then be developed allowing its use as starting material in synthetic chemistry. ${ }^{69}$ In order to do so, it is necessary to develop also strategies to protect the different hydroxyl groups. ${ }^{69}$ Other approach to employ these compounds is the use of the gluco-isosaccharinic acids as energy source for specific anaerobic bacteria that can effectively destroy chlorolignins. Thus, they could be applicable in the effluent treatment processes of the Kraft pulp mills. The studied strains showed properties as nonutilization of glucose and non-requirement of organic nitrogen may increasing the possibilities for the exploitation in biotechnological process. ${ }^{70,71}$

Another reason of interest in these acids is the influence that $\alpha / \beta$-gluco-isosaccharinic acids produced by hemicellulose peeling 
have in the safe disposal of low-intermedium level radioactive wastes. These acids have the potential to complex with tetravalent actinides, trivalent lanthanides and actinides, forming strong soluble complex. This process has an adverse impact in the radionuclides sorption on cement. ${ }^{72-74}$

Table 5 Properties of Isosaccharinic acids present in BL.

\begin{tabular}{|c|c|c|c|c|}
\hline Properties & & $\alpha$-gluco-isosaccharinic & $\beta$-gluco-isosaccharinic & Xylo-isosaccharinic \\
\hline Chemical formula & & $\mathrm{C}_{6} \mathrm{H}_{12} \mathrm{O}_{6}$ & $\mathrm{C}_{6} \mathrm{H}_{12} \mathrm{O}_{6}$ & $\mathrm{C}_{5} \mathrm{H}_{10} \mathrm{O}_{5}$ \\
\hline Molecular weight & {$[\mathrm{g} / \mathrm{mol}]$} & 180.16 & 180.16 & 150.13 \\
\hline Density & {$\left[\mathrm{g} / \mathrm{cm}_{3}\right]$} & 1.599 & 1.599 & 1.527 \\
\hline Enthalpy of vaporization & {$[\mathrm{KJ} / \mathrm{mol}]$} & 100.17 & 100.17 & 86.89 \\
\hline
\end{tabular}

*Predicted properties at $101.325 \mathrm{KPa}$ and $20^{\circ} \mathrm{C}$

**Calculated from the annual production of $\mathrm{BL}$ and an average acid content in $\mathrm{BL}$.

\section{Carboxylic acids recovery and purification technologies}

Large amounts of carboxylic acids are produced annually by the pulp and papermaking industry. From this group of acids, glycolic, lactic, formic and acetic are important industrial chemicals that are already being produced by alternative routes. In present time, the use of the other important hydroxy acids such as 3,4dideoxypentanoic, alfa/beta gluco-isosaccharinic, 2hydroxybutanoic and xylo-isosaccharinic acids have not been largely studied.

It is important to point out the distinction between hydroxy acids recovery from $\mathrm{BL}$ and their respective purification processes. The carboxylic acids recovery refers to the operations needed to extract these acids from the original mixture, BL. Moreover, the technologies preferred to integrate are those which have a low impact or no interference at all with the pulp mill industry cycle, cooking chemicals recovery and extractives obtainment. Purification is related to the technologies employed to achieve a complete selective separation to obtain pure acids.

However, the purification and separation process of the hydroxy acid fraction is a complex and laborious task that has only been achieved at laboratory scale. Techniques as membrane filtration, distillation under reduced pressure and special chromatography techniques as ion exclusion chromatography have been proposed and studied as possible purification methods. Figure 7 summarizes some of the proposed processes for hydroxy acids recovery and purification from BL. Usually a carbonation or/and acidification step is required in order to recover the lignin at the beginning of the purification process.

\subsection{Membrane filtration}

The membrane technologies have been largely studied in the last years, resulting in important applications in several manufacture processes in fields as pharmaceutical, biological, food and chemical industries. This technology is based on a simple but effective mechanical separation process, in which only a semi permeable medium and hydrostatic pressure difference, as driving force, are required. Even though the main disadvantage is associated with the fouling and cleaning cycle, this process does not require heating therefore is much more energy efficient than other conventional separation as distillation, crystallization or sublimation. According to the membrane type and the retained particle size, membranes can be classified in four main processes that differ in operation conditions and application field: reverse osmosis (RO), nanofiltration (NF), ultrafiltration (UF) and microfiltration (MF). ${ }^{75}$ Table 6 summarizes the characteristics, operational conditions and applications of the different membranes technologies. Another membrane-based separation process used in carboxylic acids recovery is the electrodialysis. There are two types of electrodialysis, both based in the same concept: ions are driven through an ionselective membrane being separated and concentrated down the influence of an electric field. 


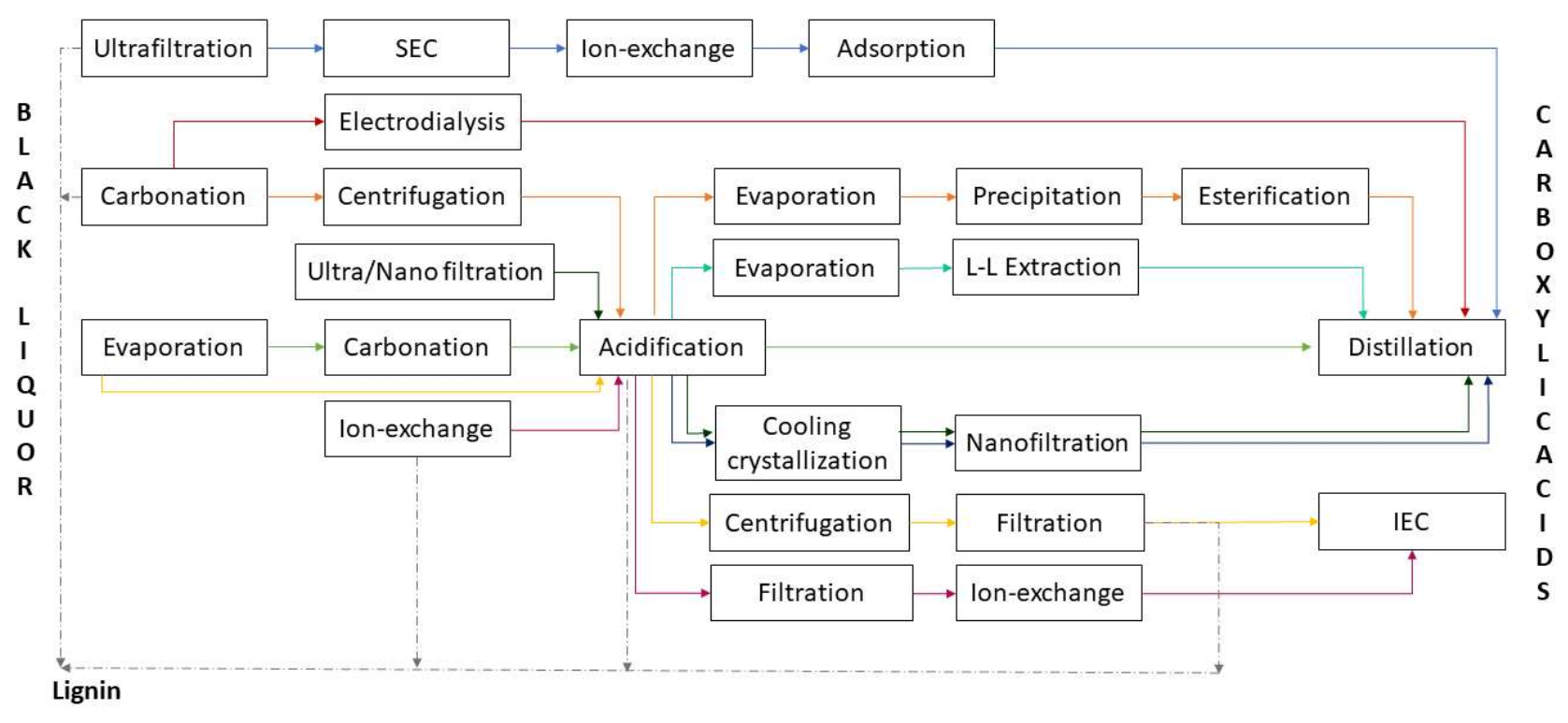

Figure 7. Routes used for recovery and purification of hydroxy acids from BL (adapted from Gallet ${ }^{76}$ ) Ultrafiltration and adsorptions ${ }^{35} \square$, Electrodialysis ${ }^{77} \mathbf{\square}$, Esterification and distillation $^{37} \square$, Ultra/Nano filtration ${ }^{34} \square$, Nanofiltration ${ }^{38} \square$, Liquid-liquid extraction ${ }^{41} \square$, Distillation under pressure ${ }^{78,79} \square$, Ion-Exclusion Chromatography $^{31} \square$, Sequential chromatographic process ${ }^{43}$

Abbreviations: $\mathrm{SEC}=$ size exclusion chromatography; L-L extraction = liquid-liquid extraction; IEC = ion exchange chromatography.

Traditional electrodialysis is composed of a cation and anion exchange membranes stacked between a cathode and an anode (Figure 8). Bipolar membrane electro dialysis consists on a stack of anion, cation and bipolar membranes, which can dissociate solvents, as for example water into $\mathrm{H}^{+}$and $\mathrm{OH}^{-}$(Figure 8). Conventional electrodialysis can be applied to concentrate and purify carboxylates, whereas the bipolar membrane electrodialysis are employed to produce free base and acid from salts. ${ }^{80}$ In pulps and paper mills, membranes are employed to purify process water and to recycle and recover valuable materials. ${ }^{81-83}$ Specifically in the Kraft pulp industry, membranes (ultrafiltration and nanofiltration) are mainly applied for purification of bleach effluent and for lignin fractionation and purification. ${ }^{84}$

Motivated by the BL concentration and the valuable compounds separation, advances have been made in membranes development. By one hand, polymeric membranes can be challenging in $\mathrm{BL}$ applications. ${ }^{83}$ The exposure of this equipment to the harsh feed conditions (relatively high temperature, fouling species and high $\mathrm{pH}$ ) can accelerate their degradation causing short lifetimes. By the other hand non polymeric membranes as ceramic present greater stability thus are expected to gain a major role. ${ }^{85}$

The technologies improvements as well as the energy integration in paper mills had led to energy surplus in many cases. This is why alternatives as lignin extraction by ultrafiltration and nanofiltration is of great interest. ${ }^{84}$ The extracted lignin can be used to replace fossilbased fuels in other manufacturing process or as feedstock for chemical production. The latter has been the target of many research effort over the last decades. ${ }^{86,87}$ As reason of the high diversity of carboxylic acids in $\mathrm{BL}$, their large range of molecular weights and deficiency of adequate separation and purification technologies, the research work carried out in this area has been scarce. ${ }^{88}$

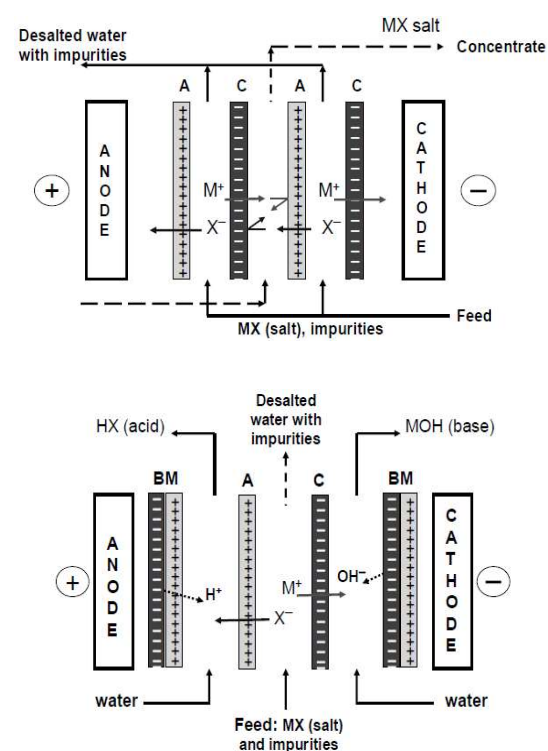

Figure 8. Top figure: Principle of desalting electrodialysis. A: anion exchange membrane; $\mathrm{C}$ : cation Exchange membrane; $\mathrm{M}+$ : cation; $\mathrm{X}-$ : anion. Bottom figure: Principle of threecompartment water-splitting electrodialysis using bipolar membranes (BM). A: anion exchange membrane; $\mathrm{C}$ : cation exchange membrane; $\mathrm{M}+$ : cation; $\mathrm{X}-$ : anions (reproduced from Yang et $\mathrm{al}^{78}$ with the authorization of Elsevier).

One of the first researches made in this field led to a patented process for recovery of low molecular weight aliphatic organic acids fraction from BL. The process comprises ultrafiltration to achieve the separation of the high and low molecular weight fraction. The permeate produced was subjected to electrodialysis, separating it into a concentrate and a deionized solution containing the aliphatic acids along with sodium lignin. The solution was then treated with acid to precipitate the lignin solids. Finally the mixture was subjected to electrodialysis water-splitting, giving as a result a low molecular weight aliphatic organic fraction. ${ }^{89}$ 
Table 6 Characteristics, operation conditions and applications of different membrane separation processes 75

\begin{tabular}{|c|c|c|c|c|c|}
\hline \multirow[b]{2}{*}{ Process } & \multicolumn{4}{|c|}{ Membrane } & \multirow[b]{2}{*}{ Applications } \\
\hline & Type & Pore size & $\begin{array}{l}\text { Driving force } \\
\text { (bar) }\end{array}$ & Material & \\
\hline MF & Symmetric microporous & $0.1-10 \mu \mathrm{m}$ & 1.-5 & $\begin{array}{c}\text { Ceramics, metal oxides (aluminum, } \\
\text { titanium, zirconium), graphite, polymers } \\
\text { (cellulose nitrate or acetate, polyamides, } \\
\text { polysulfone) }\end{array}$ & $\begin{array}{l}\text { Sterile filtration, } \\
\text { clarification }\end{array}$ \\
\hline UF & Asymmetric microporous & $1-10 \mathrm{~nm}$ & $1-10$ & $\begin{array}{c}\text { Ceramics, polysulfone, polypropylene, } \\
\text { PVC, acrylic copolymer) }\end{array}$ & $\begin{array}{c}\text { Separation of } \\
\text { macromolecular solutions }\end{array}$ \\
\hline NF & Thin-film membranes & $1-5 \mathrm{~nm}$ & $10-30$ & $\begin{array}{c}\text { Cellulosic acetate and aromatic } \\
\text { polyamide }\end{array}$ & $\begin{array}{c}\text { Removal of hardness and } \\
\text { desalting }\end{array}$ \\
\hline RO & Asymmetric skin-type & $0.5-1.5 \mathrm{~nm}$ & up to 200 & $\begin{array}{l}\text { Polymers, cellulosic acetate aromatic } \\
\text { polyamide }\end{array}$ & $\begin{array}{l}\text { Separation of salts and } \\
\text { micro solutes from } \\
\text { solutions }\end{array}$ \\
\hline
\end{tabular}

In a similar approach but this time combining membrane separation with other separation operations as acid filtration and cooling crystallization, Niemi et al. ${ }^{34}$ proposed a new process illustrated in Figure 7. This process begins with lignin separation by means of either an ultra- or nano-filtration. It was found that the membrane selection does not have a remarkable influence in the lignin removal.

The initial lignin content ( 82 g.L-1) was decreased to 18 g.L-1 and 20 g. $\mathrm{L}^{-1}$ with nano- and ultra-filtration respectively. The resulting permeate was subjected to a second lignin removal process by acid precipitation. Then filtrate solution went through cooling crystallization to remove inorganic compounds prior to the recovery of the organic acid fraction by a second nanofiltration. By combining these operations, it was able to achieve a decrease of the initial lignin content and organic compounds of $90-95 \%$ and $70-75 \%$, respectively. The authors suggested that further purification of the hydroxy acids could be achieved by chromatography or tight nanofiltration. ${ }^{34}$

Another multistep process for the recovery of hydroxy acids from BL was proposed by Mänttäri et al. ${ }^{20}$ The process comprises four separation steps: ultrafiltration, size-exclusion chromatography, ion exchange and absorption to obtain the hydroxy acids mixture that can be further purified by distillation. As discussed before the membrane technology is not enough to achieve recovery thus is generally employed as a pre-treatment or as a part of an ensemble of purification methods. In this case the ultrafiltration removes most of the lignin present in the $\mathrm{BL}$ prior to the size-exclusion chromatography (SEC). The obtained permeate is processed to separate the $\mathrm{NaOH}$ and the hydroxy acids that were further collected as different fractions. Due to the operational conditions employed in the SEC, especially $\mathrm{pH}$, the carboxylic acids recovered where present as salts. An exchange resin was used to remove the residual sodium and to liberate the acids. Though the ultrafiltration removed most of the lignin, some of it remained in the samples, later removed by adsorption on a neutral hydrophobic polymer resin. Finally, the hydroxy acids fractions were concentrated by vacuum evaporation. This process led to a $99 \%$ of lignin removal, almost complete sodium extraction and a range between $63-81 \%$ (mass basis) of purity in the hydroxy acids fraction. Even though the process was developed for soda BL, it can be slightly modified to be applied in Kraft BL. In this case, special attention is required regarding the safety of the process in the ion exchange step, where hydrogen sulfide may be formed. ${ }^{20}$ The flow sheet of this process is presented in Figure 7.

In a more recent study H. Kumar \& R. Alén ${ }^{77}$ described a process for partial recovery of $\mathrm{NaOH}$ and carboxylic sodium free acids. In this case, two different setups and approaches were evaluated. The initial phase was common for both scenarios: BL was treated with carbon dioxide to precipitate lignin ( $c a .59 \%$ ), then the carbonated $\mathrm{BL}$ was further processed according the technology. This resulting solution was mainly composed by the remaining lignin, sodium salts of aliphatic carboxylic acids and $\mathrm{NaHCO}_{3} / \mathrm{Na}_{2} \mathrm{CO}_{3}$. In the first scenario (Figure 7 - Electrodialysis) the carbonated $\mathrm{BL}$ was diluted with water (1:5) and then evaporated to recover the volatile acids prior to electrodialysis in which the $\mathrm{NaOH}$ and the free hydroxy acids were obtained. ${ }^{77}$

In the second approach, the carbonated BL was first acidified to decrease the lignin content ( $c a .90 \%$ ), then treated with methanol to precipitate the $\mathrm{Na}_{2} \mathrm{SO}_{4}$ formed. This latter compound was finally electrodialyzed to recover $\mathrm{H}_{2} \mathrm{SO}_{4}$ and $\mathrm{NaOH}$. The solution that mostly contains methanol and the hydroxy carboxylic acid fraction can be further processed by distillation aiming a higher purity of the sodium free carboxylic acids. It was achieved, for both cases, a sodium recovery around $90 \%$. The carbonated BL that was further delignified and then electrodialyzed led to a carboxylic acids recovery of $80 \%$ of the initial diluted solution. ${ }^{77}$

Continuing with a similar approach to the one suggested by Niemi et al., ${ }^{34}$ Mänttäri ${ }^{90}$ carried out the most recent study in organic acids purification making use of the membrane technology found in the literature. In this configuration, the BL delignification was achieved by the use of an ultrafiltration membrane and acid precipitation to remove the remains. These processes were followed by cooling crystallization, nanofiltration and absorption to recover and purify the acid fraction, the low sheet of the process is illustrated in Figure 7. The membrane used in the nanofiltration step was 
probed to be effective in the organic acids fractionation due to the significantly higher retention of isosaccharinic acids in comparison to glycolic, lactic and volatile acids. Thus, not only a fractionation but some hydroxy acids separation was achieved. It was also demonstrated that the ultrafiltration step had a great influence in the hydroxy acid purity. At the end of the process, without this step an increase from $21 \%$ to $80 \%$ in the acids purity was achieved in the NF permeate. ${ }^{90}$

The new approaches combining membranes and crystallization might be an interesting alternative to the hydroxy acids recovery and purification. ${ }^{34,91}$ Regarding the use of the membranes in the lignin removal from $\mathrm{BL}$, this technology might be advantageous in comparison to the precipitation with mineral acids, which can cause difficulties in further processing due to the colloids formed in this process. Furthermore, the use of membranes in acid purification can be seen as a component of a full process rather than its individual use. Membranes fouling is the major concern when these technologies are employed, highlighting the importance of effective delignification pre-treatments prior to membranes use. Another drawback is related to the pore size distribution that can limit the efficient separation when working with fraction containing a narrow molar mass dispersion. Despite the challenges that the use of membranes may have, these can be considered as future solutions due to their separation potential with low energy consumption. The integration of these technologies to the existing process can allow the recovery of valuable solutes, improving the economy of the biomass refining structure in the pulp mills.

\subsection{Ion and size exclusion chromatography}

Chromatography has shown to be effective in carboxylic acids purification. ${ }^{92}$ The components, molecules or ions, are separated based on differences in the migration velocities while passing through a stationary phase, usually a bed of solid particles packed in a column. ${ }^{93}$ Differences in the partition coefficients of the compounds result in a differential retention on the stationary phase. Attraction forces between the solutes and the solid phase (adsorption), electrostatic effects (ion-exclusion) and steric effects (size-exclusion) can affect the partitioning, thus, the migration velocity. ${ }^{94}$ Based on these phenomena, different types of chromatographic techniques can be developed as shown in Figure 9.

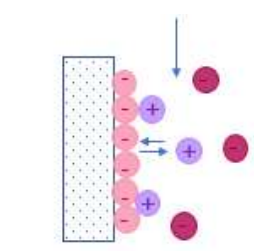

lon-exchange Chromatography

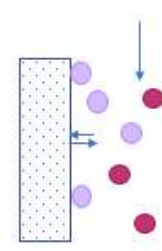

Adsorption Chromatography

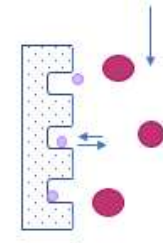

Size-exclusion Chromatography
Figure 9. Main types of liquid chromatography based on their separation mechanism.

This technique is largely employed in fields covering from biotechnology to fine chemicals production. The main advantages of chromatography over other separation technologies are related to energy requirement, chemical consumption and downstream volumes. ${ }^{95}$ Chromatography can fulfill two basic functions: measure the proportion of the components of the mixture (analytical purpose), and separate the components of the mixture to obtain them purer and then be used in final stage of many syntheses. ${ }^{93}$ In the pulping and papermaking industry, studies have been carried out on both approaches. However, chromatography techniques for analytical purposes are out of the scope of this review.

Ion exclusion chromatography has been successfully employed in weak acids separation, particularly hydrophilic aliphatic carboxylic acids. ${ }^{92,96}$ Alén et al. ${ }^{31}$ carried out a pilot scale study targeting the separation of hydroxy carboxylic acids present in $\mathrm{BL}$ from inorganic solids. The solution was first treated with sulfuric acid to liberate the hydroxy acids and to remove most of the lignin. The multistep separation process employed columns packed with strong acid polystyrene cation exchange resin cross-linked with $4 \%$ divinylbenzene. ${ }^{31}$ The process is illustrated in Figure 7 and further specified in Figure 10.

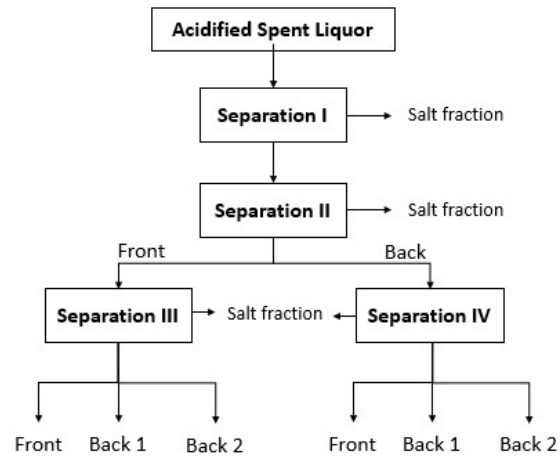

Figure 10. Multistep ion-exclusion chromatography for hydroxy acid separation (reproduced from Alén et $\mathrm{al}^{31}$ with the authorization of John Wiley and Sons)

Delignified BL was fed to the column using water as eluent producing two different fractions. The first one mainly composed by hydroxy acid that eluted slower (back fraction) and the second one consisting in sodium sulfate. Two separation steps were needed to achieve the sodium sulfate removal which was highly concentrated in the initial liquor. From separation II four different fractions were obtained according to elution order (A, B, C,D), front fractions (A, B) were poorer in hydroxy acids. Separation IIA had the lowest acid loading whereas the Separation IID presented the high loading in hydroxy acids with a recovery of $65 \%$ and $95 \%$ purity. Further separations were carried out with the front and back fractions (Separation III and IV) the purity was high even in the fractions from separation III that was fed by the previous front fractions (poorer in hydroxy acids).

In order to study the differences in the retention times between the individual hydroxy acids the fraction IID was subjected to further purification. It is important that as long as the separation conditions were acidic, some hydroxy acids can be present as their respective lactones. The different forms of gluco-isosaccharinic acid (including lactones) along with the dicarboxylic acid, eluted faster than lactic and glycolic acid. The highest concentration obtained was $45 \%$ glucoisosaccharinic acid, 30\% glycolic acid, 25\% lactic acid and $15 \%$ dicarboxylic acid together with the volatile acid. Acid strength, lactonization tendency as well as steric effects may had an influence in the elution order of the compounds. ${ }^{31}$

Size exclusion chromatography has also been found suitable for hydroxy acids recovery from BL by S. Hellstén et al. ${ }^{36} \mathrm{BL}$ from soda hard and softwood cooking was ultrafiltrated before being used as a feed for the chromatographic column containing Sephadex G-10 as the stationary phase and purified water as eluent. The lignin content in the product fraction was low and the hydroxy acids were 
successfully separated from sodium hydroxide. The principal advantage of using SEC over other separation methods is that lignin precipitation by acidification prior separation is not required. SEC treatment increased the total hydroxy acid purity by $30-40 \%$ in reference to their composition in the feed stream. Glucoisosaccharinic and xylo-isosaccharinic acids were the first eluting hydroxy acids that can be recovered in high purity whereas the smaller hydroxy acids fraction contains also a small amount of $\mathrm{NaOH}$. The optimization of this process showed that column loadings can be increased without compromising either purity or yield. The $\mathrm{NaOH}$ and sodium salts separation from hydroxy acids was not affected by fouling of the separation medium, however the authors concluded that the long-term exposition of Sephadex G10 to alkaline medium may decompose the dextran polymer requiring further investigation. Even though soda and Kraft BL hydroxy acids content might be similar, the use of this technique in the latter can be more complex. Related to its molecular size, sulfur compounds present in BL are more difficult to separate than $\mathrm{NaOH}$. Additionally, as discussed before, in the membranes technologies section, when working with Kraft BLs, hydrogen sulfide can be formed during the hydroxy acid fraction processing. ${ }^{36}$

SEC can also be used as a part of a hybrid multistep separation process in the hydroxy acid recuperation from $B L$ as it was exposed before in the membrane separation technologies. ${ }^{20}$ Besides hydroxy acids recovery SEC had been studied for other biorefinery applications as lignosulphonates fractionation and oligosaccharides from steam-treated wood. Nevertheless, the viability of sizeexclusion gels exposed to the harsh conditions in a long-term use has not been established. ${ }^{97,98}$

J. Heinonen et al. ${ }^{43}$ proposed a consecutive chromatographic separation process to recover hydroxy acids but at the same time allowing spent chemicals and lignin to be recycled. Kraft and soda spent cooking liquors were used as feed. The delignification and $\mathrm{NaOH}$ removal were common for both feeds and were carried out by SEC with GA 10G-Na+ and GH-25 in order of use. For this first step a $95 \%$ and $50 \%$ yield were obtained for lignin and hydroxy acid salts, respectively. A complete separation between the acid mixture and the $\mathrm{NaOH}$ was achieved by a cellulo-based resin. From this point onwards the final recovery of the product was different according to each case. For the soda, the liberation of the acids from the salt form was achieved by ion exchange to obtain the final fraction, whereas the Kraft required acidification followed by filtration prior to the acid liberation. Moreover, the latter was further subjected to exclusion chromatography in order to recover the remaining cooking chemicals. The more complex separation process Kraft cooking liquor can be justified by the fact that $\mathrm{Na}_{2} \mathrm{~S}$ may form species such as $\mathrm{H}_{2} \mathrm{~S}$, $\mathrm{CO}_{2}, \mathrm{SO}_{2}$ during acidification (Figure 7 Sequential chromatographic process). The recovered $\mathrm{H}_{2} \mathrm{SO}_{4}$ can be employed either for acidification or to regenerate the resin used in $\mathrm{Na}$ removal, this process would generate at the same time $\mathrm{Na}_{2} \mathrm{SO}_{4}$, which can be transformed in $\mathrm{Na}_{2} \mathrm{~S}$ in the reboiler unit, closing the recycling loop. Even though the final purification was more complicated, the recovery of the acid fraction was accomplished for both case scenarios, not single acid isolation was achieved. ${ }^{43}$

J. Heinonen and T. Sainio ${ }^{42}$ carried out a four-step sequential chromatographic separation process. In this case, the fractionation of the hydroxy acids mixture led to the complete isolation of some of the main acids in high purity. The separation process (Figure 11) was based on hydrophobicity, acids strength differences and the ISA intramolecular lactonization tendency. Hydrophobicity played the major role when working with polymeric adsorbents whereas for the strong base anion resin was the intramolecular lactonization and strength difference which allowed the separation. In the first step (I) the 2-HBA was completely separated from the BL-based acid mixture. The 2-HBA fraction was then concentrated by evaporation in reduced pressure, concentration was carried out prior each separation. A second separation process (II) allowed the complete recovery of the isosaccharinic acids fraction, which was further treated (III) obtaining a xylo-isosaccharinic acid and glucoisosaccharinic acid as high purity products. The second outstream from the second separation containing glycolic, lactic and 2,5dihydroxypentanoic acid was also subjected to another chromatographic separation (IV). In this case, the isolated compound was the glycolic acid; no further separation was carried out for the lactic and 2,5dihydroxypentanoic acid acids mixture. Softwoods usually presents a lower 2-hydroxybutyric acid in comparison to hardwood, therefore the first step (2-hydroxybutyric acid) removal may not be required. ${ }^{42}$

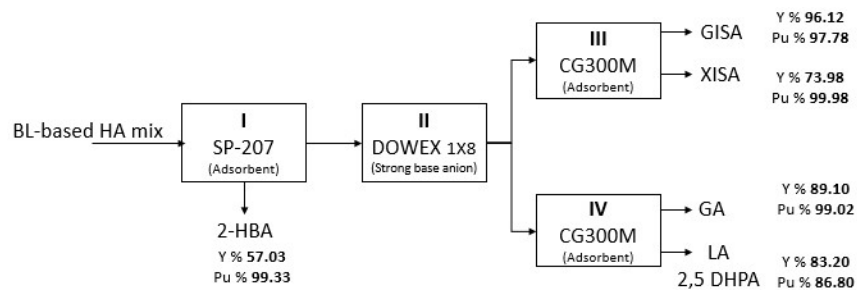

Figure 11. Sequential chromatographic separation process for BL-based HA mixture (reproduced from Heinonen et $\mathrm{al}^{42}$ under the terms of the Creative Commons CC-BY license).

Abbreviations: $\mathrm{HA}=$ hydroxy acids; GISA = gluco-isosaccharinic acids; XISA = xyloisosaccharinic acids; $\mathrm{GA}=$ glycolic acid; $\mathrm{LA}=$ lactic acid; 2,5 DHPA $=2,5-$ dihydroxypentanoic acid.

In another approach, this time with a hybrid process, J. Heinonen, et al. ${ }^{99}$ proposed and ion exchange and electrodialysis system. This technology integrates the hydroxy acids recovery with cooking chemicals restitution. Lignin and sodium hydroxide free soda and Kraft BL were used as feed for the process (Figure 12). The hydroxy acids recovery, liberation from the salt form and $\mathrm{H}_{2} \mathrm{SO}_{4}$ separation were carried out by anion/cation exchange and electrolyte exclusion. The latter was only required when working with Kraft $\mathrm{BL}$ due to the presence of $\mathrm{NaS}_{2} \mathrm{O}_{3}$ and $\mathrm{Na}_{2} \mathrm{SO}_{4}$, making the procedure more complex. ${ }^{99}$ 


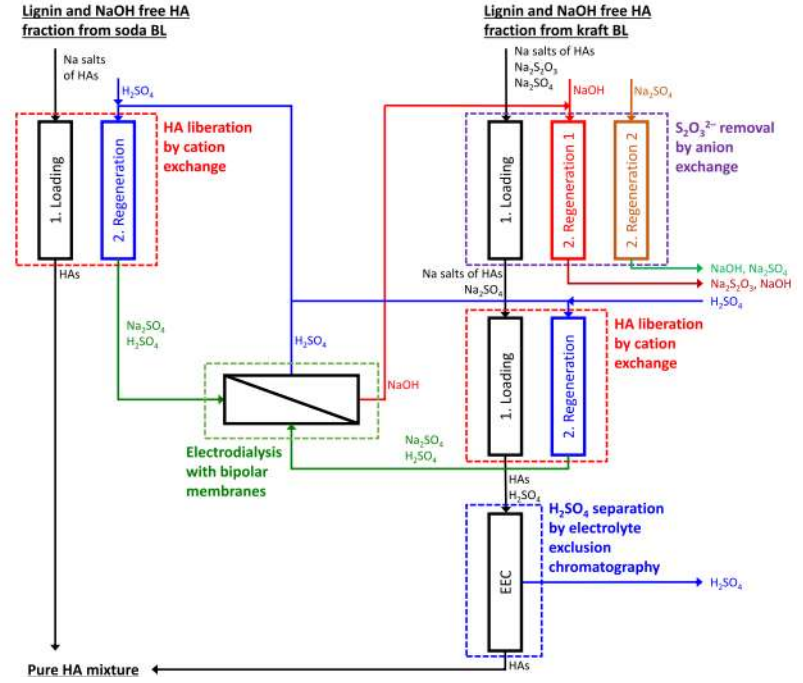

Figure 12. Hydroxy acids production from Soda and Kraft BL with a closed loop of cooking chemical recovery (reproduced from Heinonen et al ${ }^{99}$ with the authorization of Elsevier).

The cooking chemicals were regenerated by electrodialysis with bipolar membranes. From this process, two out streams are obtained, $\mathrm{H}_{2} \mathrm{SO}_{4}$ and $\mathrm{NaOH}$, which can be either integrated to regenerate the spent cation/anion resins or recycled into the digester. Moreover, this technology allows to close the loop and to reduce the overall chemical consumption related to the hydroxy acids production. ${ }^{99}$

In contrast to the membrane technologies, chromatography has proven to be effective as a unique method of separation, in consecutive processes in which one or more different chromatographic techniques may be present. This does not detract from the fact that it can also be integrated as an important step into more complex separation systems. However, chromatographic BL processing can face a similar problem as membranes regarding the harsh feed conditions, in this case not only material degradation and fouling but clogging due to precipitates should be taken in account. The first two problems can be addressed or avoided by the appropriated choice of the chromatographic material. Studies carried out in this field have led to overcoming one of the main problems in the $\mathrm{BL}$ downstream treatment, lignin removal prior purification, which is commonly the main cause of the implementation of hybrid separations. Moreover, recovery of high purity isolated isosaccharinic acids can be achieved by a sequential chromatographic separation process. Furthermore, recent advances in $\mathrm{BL}$ applications have led to development processes that can be fully integrated in the pulp mills without affecting internal recovery cycles.

\subsection{Distillation}

Volatile compounds such as acetic and formic acid can be separated by distillation. ${ }^{80}$ However, nonvolatile compounds may require to be transformed to their corresponding ester prior distillation followed by a hydrolysis step in order to be effectively recovered as in the case of lactic acid. ${ }^{100,101}$

Alén and Sjöström ${ }^{78,79}$ studied for the first time the hydroxy acids separation of a crude acids fraction from BL by distillation (Figure 7 Vacuum distillation). The liquor samples were treated with $\mathrm{CO}_{2}$ and $\mathrm{H}_{2} \mathrm{SO}_{4}$ lignin removal, which was subjected to further purification to remove volatile acids and inorganic salts. The resulting crude fraction contained approximately $60 \%$ of hydroxy acids being $\beta$-gluco- isosaccharinic the highest constituent (27.3\%). Working at distillation pressures of $0.067-0.173 \mathrm{KPa}$, around of $45 \%$ of the total hydroxycarboxylic acids were recovered, being glycolic, lactic, 2hydroxy butanoic, and isosaccharinic acids the main components. The small hydroxy acids were more difficult to separate in comparison to XISA and GISA due to their narrow difference in boiling points. The authors concluded that distillation can be seen as a suitable technique for hydroxy acids separation and it was suggested that previous esterification may enhance the fractionation of individual acids. ${ }^{78,79}$

Following this approach for acids purification, H. Kumar and R. Alén ${ }^{37}$ proposed a recovery process that begins with a similar acidification step as described in their earlier work for lignin removal and acids liberation. A recovery of approximately $65 \%$ percent of the total acids was achieved within the process illustrated in Figure 7, esterification and distillation, 50\% represents volatile acids and the remaining $15 \%$ are the low molecular hydroxy acids. In this study, volatile acids were recovered by straightforward distillation, whereas the low carboxylic acids such as glycolic, lactic and 2hydroxybutanoic acids were transformed in their corresponding esters prior distillation. The esterification was carried out at $70^{\circ} \mathrm{C}$ in presence of an acid catalyst (Amberlyst $150.2 \%$ wt.) with a methanol excess. The parameters optimization for the esterification led to yields of $71.4 \%, 70.4 \%$ and $84.3 \%$ of methyl glycolate, lactate and 2 hydroxybutanoate respectively. The preliminary experiments gave a hint regarding the relative volatiles, values of 1.0, 1.7 and 1.6 were obtained and no azeotropic formation with methanol was observed, implying the feasibility of the separation process. However, this approach left a residual outstream composed by high molecular hydroxy acids such as 3,4-dideoxy-pentonic, 3-deoxy-pentonic, and isosaccharinic acids which required further purification process. ${ }^{37}$

Distillation has been found to be a suitable technique for separating volatile acids. However, due to the narrow boiling point difference in some of the high molecular weight acids, simple distillation is not adequate. This can be overcome by esterification with alcohols such as methanol and ethanol to increase the difference in volatilities thus making feasible their separation trough distillation. The recovered products, esters, must be subjected to hydrolysis to be returned to their acid form. Nevertheless, it is important to highlight that distillation is usually an energy intensive technique thus process parameters optimization is required. Although this technique has not largely been exploited for carboxylic acids recovery from BL it has inherent advantages that can be of great interest in this mixture separation. By one hand this wellknown intensification technique makes possible to pull the equilibrium to high conversion working at stoichiometric reactants ratio, avoiding the use of reactant excess, due to the continuous removing of the products. ${ }^{102,103}$ By the other hand, it has been proved to be applicable in separating and isolation of valuable constituents from complex broths. This technology was successfully tested in the separation of succinic and acetic acids from fermentation of biomass carbohydrates. ${ }^{104}$ It has also been studied as an alternative for multicomponent azeotropic mixtures as the case of formic and acetic acid. ${ }^{105}$ Both cases showed a complete removal or isolation of desired products by changing the compounds properties, protecting the acid function, trough chemical reactions thus establishing itself as an interesting alternative to explore in this field.

\subsection{Liquid-Liquid Extraction}


One of the principal technologies to recover carboxylic acids from diluted aqueous systems as for example diluted fermentation mixtures is extraction. ${ }^{106-108}$ Effective recovery of some important carboxylic acids as acetic, succinic, lactic, propionic and citric acids by liquid-liquid extraction have been reported in literature. ${ }^{109}$ Solvent extraction or liquid-liquid extraction is based on the partition of the component to be extracted in two immiscible phases, an aqueous and an organic phase, usually the solvent. ${ }^{110}$ Typically, these solvents can be categorized in three main types: high molecular weight aliphatic amines, oxygen bearing and hydrocarbon solvents and phosphorus-bonded oxygen bearing extracts. Furthermore, recent studies have shown that ionic liquids can also be employed in acids recovery from diluted mixtures, however its main drawbacks are cost and low partition coefficients. ${ }^{80}$ In recent years, this technology has been studied in the treatment of Kraft BL.

G.-H. Kim et al. ${ }^{41}$ studied the feasibility of recovering carboxylic acids from $B L$ by liquid-liquid extraction with trioctylphosphine oxide (TOPO). The study aimed the carboxylic acids extraction in a biorefinery plant integrated to a pulp mill for the production of fermentation derived alcohol. A simplified diagram of this process is illustrated in Figure 7, liquid-liquid extraction. An acid hydrolysis step was required prior fermentation in order to hydrolyze oligomeric sugars and at the same time achieving lignin removal. Temperature, reaction time, concentration of the hydrolyzed and $\mathrm{pH}$ were the evaluated operating conditions. It was found that at optimal conditions, $\mathrm{pH} 1$ and $25^{\circ} \mathrm{C}$ (reaction time showed no response), extraction yields of $71.7 \%, 75.1 \%$, and $65.0 \%$ for acetic acid, formic acid, and lactic acid, were obtained, respectively. ${ }^{41}$

A study aiming the extraction of polyphenols, polysaccharides and lactate present in BL was carried out by J-P Magnin et al. ${ }^{111}$ Due to hydrophobic nature and large commercial availability, two ionic liquids based on phosphonium cations with either $\mathrm{Br}$ or $\mathrm{Cl}$ anions were tested as extractive solvents. Polysaccharides extraction yield was not affected weather were treated by trihexyltetradecylphosphonium chloride (93.5\%) or trihexyltetradecylphosphonium bromide (93.3\%), whereas polyphenols and lactate recovery was impacted by the ionic liquid chosen. Polyphenols extraction proved to be less effective in $\left[\mathrm{P}_{66614}\right] \mathrm{Br}(71.5 \%)$ in comparison to $\left[\mathrm{P}_{66614}\right] \mathrm{Cl}(94.1 \%)$, opposite case for lactate where the extraction yields were $69.0 \%$ and $45.0 \%$ correspondingly. ${ }^{111}$

Even though this technology has been proved to be effective in acids recovery from diluted fermentation mixtures, positioning it as an interesting alternative to apply in downstream Kraft treatments, it has not been extensively investigated. Furthermore, the studies employing this separation technique have targeted the extraction of specific acids. Carboxylic acids are recovered in their salt form thus requiring an acidification step. Additionally, the solvents have to be regenerated by either stripping or distillation increasing the number of units then the complexity of the process. Finally, further studies in this field are required aiming to find or develop efficient solvents to extract organic acids in an efficient energy and economic perspective.

In order to extract and purify the carboxylic acid fraction from $\mathrm{BL}$ different techniques had been proposed as feasible processes to be integrated in the pulp mills. However, each one of these carries some advantages as well as drawbacks that need to be considered. Furthermore, the selection of the technology requires a deep analysis involving not only yield but the economics and environmental impact of the choice. A compilation of the main separation techniques, description, advantages and drawbacks are summarized in Table 7.

\section{Conclusion}

In the last decades pulp and paper production industry has faced the challenge of becoming an integrated forest biorefinery (IFBR) enabling the increase in its revenue by producing biomaterials, chemicals and energy. The main challenge is the complete integration of the new process to the traditional ones without intervening in the cooking chemical recycling or as much as possible, improving them. Although this process is practically energy selfsufficient, the biggest obstacle is generally related to energy production in recovery reboiler. BL is fed to the reboilers, allowing recovering the cooking chemicals and at the same time producing energy. Generally, a surplus of energy is produced due to the large amounts of BL generated, this being the bottleneck of the process. The composition of BL strongly depends on the pulping process and the type of feedstock employed; however, the composition is roughly the same from a qualitative point of view. Carboxylic acids stand out from the main compounds of this liquor having a low heating value, thus their recovery, purification and further transformation into valuable feedstock and building block materials is much more appealing than energy source.

Research efforts have led to the development of recovery and purification processes. Different technologies had been studied for aliphatic acids recovery from BL. However, this represents a complex separation process which has so far only achieved at laboratory scale. The separation and further purifications of these acids is difficult to achieve due to low vapor pressures, similar solubility properties and presence of impurities among others. Moreover, among the main acids found, there is no homogeneity in the data related to them, since some are widely described in the literature and with applications already established in the industry, while others have not yet been extensively studied and their potential applications have not been industrialized.

Chromatographic techniques as well as hybrid separation methods including membranes are the most traditional ones. Nevertheless, the main problems that these technologies encounter are the harsh mixture conditions and the fact that generally long complex processes (multi steps) are required. Thus, the logic step to follow in the evolution of these technologies should aim to study these materials in a long-term use as well as and the development, if necessary, of new materials adapted to the conditions. Other approaches as solvent extraction and reactive distillation had been recently proposed as alternatives, related to the successful use of these methods in other carboxylic acids mixtures. From the latter ones reactive distillation stands out as the most promising one, as it has been proven to be effective in carboxylic acids recovery, volatile acids as well as hydroxy acids, from different broths. Still, the main challenges to face are the conditions and energetic optimization of the process to be effective thus further studies targeting these issues are required. It is important to highlight that although some of the proposed technologies appear to be efficient and promising, they have only been tested at the laboratory level, and in most cases require further optimization before being integrated to the pulp mills. 
The chemical valorization of carboxylic acids from black liquor requires intensive investigation before designing intensified, ecofriendly recovery processes. At the moment, only laboratory scale studies were published in literature. In the future, research should be focused on the analysis of black liquor composition to improve the knowledge on chemical structures present. For membrane separation and chromatographic separation, the ageing of materials and their ability to be regenerated or recycled is crucial for their application at industrial scale; the design of effective distillation processes, integrating a reactive step and working with crude black liquor, is also necessary; studies on liquid-liquid extraction applied to real black liquors is mandatory. For all mentioned processes, the fate of other compounds mentioned in black liquor, such as lignin or inorganic salts, must be elucidated before any transfer to industry.

\section{Acknowledgments}

Laura Reyes thanks the Ecole Doctorale de Chimie de Lyon for her PhD grant. 


\begin{tabular}{|c|c|c|c|c|c|}
\hline \multirow[b]{2}{*}{ Membranes } & $N F, U F$ & $\begin{array}{l}\text { Retaining suspended solids and } \\
\text { substances in a specific range of } \\
\text { size by hydrostatic pressure } \\
\text { difference as driving force }\end{array}$ & $\begin{array}{l}\text { No heating required then more } \\
\text { energy efficient. However still } \\
\text { remains the cost associated with } \\
\text { compression/vacuum which also } \\
\text { plagues the energy efficiency of } \\
\text { the process. }\end{array}$ & $\begin{array}{l}\text { Membrane fouling and cleaning } \\
\text { cycle, usually employed as a step } \\
\text { rather than a hole separation } \\
\text { process. High dilution of output } \\
\text { streams. }\end{array}$ & $\begin{array}{l}\text { Low energy consumption (no } \\
\text { heating), except for ED, no } \\
\text { solvent or chemical additive } \\
\text { required. } \\
\text { Membrane synthesis and }\end{array}$ \\
\hline & ED & $\begin{array}{l}\text { Extraction of ionized substances } \\
\text { dissolved in an aqueous solution } \\
\text { through selective ion exchange } \\
\text { membranes under the influence } \\
\text { of a continuous electric field }\end{array}$ & $\begin{array}{l}\text { Allows the recovery of cooking } \\
\text { chemicals closing the recycle } \\
\text { loop }\end{array}$ & $\begin{array}{l}\text { High energy consumption, } \\
\text { membrane fouling, further } \\
\text { purification may be required }\end{array}$ & $\begin{array}{l}\text { regeneration and recycling can } \\
\text { have a high environmental } \\
\text { impact. } \\
\text { High consumption of energy to } \\
\text { recover the acids from diluted } \\
\text { streams. }\end{array}$ \\
\hline Chromatography & $\begin{array}{l}\text { Adsorption } \\
\text { Ion-exchange } \\
\text { Size exclusion }\end{array}$ & $\begin{array}{c}\text { Separation based on differences } \\
\text { in the migration velocities while } \\
\text { passing through a stationary } \\
\text { phase }\end{array}$ & $\begin{array}{l}\text { Some configurations allow to } \\
\text { avoid the lignin precipitation } \\
\text { (lowering chemicals } \\
\text { consumption), recovery of high } \\
\text { purity isolated acids }\end{array}$ & $\begin{array}{l}\text { Different steps and techniques } \\
\text { required to achieve complete } \\
\text { isolation thus must be optimized } \\
\text { from an economic point of view }\end{array}$ & $\begin{array}{l}\text { Low energy consumption (no } \\
\text { heating), organic solvents may be } \\
\text { required. } \\
\text { High consumption of energy to } \\
\text { recover the acids from diluted } \\
\text { streams. }\end{array}$ \\
\hline Distillation & $\begin{array}{l}\text { Distillation } \\
\text { Esterification and } \\
\text { distillation }\end{array}$ & $\begin{array}{l}\text { Separation based in the relative } \\
\text { volatilities differences of the } \\
\text { components present in the liquid } \\
\text { mixture }\end{array}$ & $\begin{array}{l}\text { Straight forward distillation } \\
\text { allows volatile acids removal. } \\
\text { Esterification prior distillation } \\
\text { may grant wider volatilities } \\
\text { intervals enabling separation of } \\
\text { compounds with narrow boiling } \\
\text { points. Also opening up the } \\
\text { possibility of new markets for } \\
\text { esters recovered }\end{array}$ & $\begin{array}{l}\text { High energy and capital costs } \\
\text { demand, esters hydrolysis is } \\
\text { required to recover the } \\
\text { carboxylic acids }\end{array}$ & $\begin{array}{l}\text { High energy consumption, } \\
\text { requires a supplementary } \\
\text { reaction (esterification). } \\
\text { Esters can be produced with high } \\
\text { purity without any solvent } \\
\text { elimination needed. }\end{array}$ \\
\hline Extraction & $\begin{array}{l}\text { liquid-liquid } \\
\text { extraction }\end{array}$ & $\begin{array}{l}\text { Component partition from } \\
\text { heterogeneous liquid mixture based } \\
\text { on their different solubilities in two } \\
\text { different immiscible liquids }\end{array}$ & $\begin{array}{l}\text { Suitable for diluted acids } \\
\text { mixtures }\end{array}$ & $\begin{array}{l}\text { Acids recovery in their } \\
\text { corresponding salt form, } \\
\text { extractant regeneration is } \\
\text { required usually by stripping or } \\
\text { distillation }\end{array}$ & $\begin{array}{l}\text { Low energy consumption, extra } \\
\text { solvents needed with potential } \\
\text { toxicity issues. Consumption of } \\
\text { energy to recover the acids } \\
\text { from diluted streams. }\end{array}$ \\
\hline
\end{tabular}




\section{References}

1 P. Bajpai, Biermann's Handbook of Pulp and Paper: Volume 1: Raw Material and Pulp Making, Elsevier, Third Edit., 2018, vol. 1. FAO report, Global Forest Products Facts and figures 2018 2018.

J. Martin and M. Haggith, The State of the Global Paper Industry 2018, Environmental Paper Network report, 2018.

4 H. Sixta, Handbook of Pulp, Lenzing, Second Edit., 2006, vol. 1-2.

5 C. J. Biermann, Pulping and Papermaking, Academic Press, Corvallis, Second Edit., 1996.

E. K. Vakkilainnen and H. Tran, Advances in the kraft chemcial recovery process, Research report - University of Toronto, 2007, 1-8. R. Alén, S. Rytkonen and P. McKeough, J. Anal. Appl. Pyrolysis, 1994, 31, 1-13.

2008, 52, 5, 747-763.

9 K. Möllersten, L. Gao, J. Yan, and M. Obersteiner, Renew. Energy, 2004, 29, 9, 1583-1598, N. Berglin, M. Lindblom, and T. Ekbom, Colloq. Black Liquor Combust. Gasif., 2003, 13.

11 M. Naqvi, J. Yan, and E. Dahlquist, Appl. Energy, 2012, 90, 1, 24-31.

G. Mongkhonsiri, R. Gani, P. Malakul and S. Assabumrungrat, Comput. Chem. Eng., 2018, 119, 70-84. J. Lehto and R. Alén, Holzforschung, 2015, 69, 257-264.

E. Wetterlund, Optimal localisation of next generation biofuel production in Sweden -Part II. Report No 2013:26, f3 The Swedish Knowledge Centre for Renewable Transportation Fuels, Sweden. Available at www.f3centre.se, 2013. M. Hamaguchi, M. Cardoso and E. Vakkilainen, Energies, 2012, 5, 2288-2309. S. Yu, S. S. Wu, Y. Liu, L. Li and X. Ge, J. Taiwan Inst. Chem. Eng., 2020, 109, 26-34. . F. Demuner, J. L. Colodette, A. J. Demuner and C. M. Jardim, BioRes., 2019, 14, 7543-7581. L. Dessbesell, M. Paleologou, M. Leitch, R. Pulkki and C. Xu, Renewable and Sustainable Energy Rev., 2020, 123, 109768. P. Zhu, O.Y. Abdelaziz, C.P. Hulteberg, A. Riisager, Current Opinion in Green and Sustainable Chem., 2020, 21, 16-21. S. Hellstén, J. Lahti, J. Heinonen, M. Kallioinen, M. Mänttäri and T. Sainio, Chem. Eng. Res. Des., 2013, 91, 2765-2774. L. Pola, S. Collado, P. Oulego and M. Díaz, Bioresour. Technol., 2019, 284, 105-114.

H. Kumar, Novel Concepts on the Recovery of By-products from Alkaline Pulping, Research report / Department of Chemistry, University of Jyväskylä, 2016. S. Kumar, L. Sahu, S. Behera and R. C. Ray, in Bioprocessing for Biomolecules Production, 2020, pp. 195-209. E. Sjöström, in Wood Chemistry: Fundamentals and Applications, 1993, pp. 71-89. R. Alén, Pulp Mills and Wood-Based Biorefineries, Elsevier B.V., 2015. T. Paloheimo, H. Pakkanen and R. Alén, Characterization of dissolved material during softwood alkaline pulping, proceedings - Second Workshop on Chemical Pulping
Processes, 2007.

H. Sixta, Biomass pretreatment and fractionation-Kraft Pulping Chemistry: Carbohydrates, lecture - Aalto University - School of Chemical Engineering, 2016

G. Mortha and A. Dupont, Chimie des procédés de fabrication des pâtes lignocellulosiques écrues, Tech. Ing. Report AF6821 v1, 2016, 33, 25.

N. G. V. Fundador, Y. Enomoto-Rogers, A. Takemura and T. Iwata, Carbohydr. Polym., 2012, 87, 170-176.

K. Niemelä, R. Alén and E. Sjöström, Holzforschung, 1985, 39, 167-172.

R. Alén, E. Sjöström and S. Suominen, J. Chem. Technol. Biotechnol., 1991, 51, 225-233.

K. Niemelä and R. Alén, Analytical methods in wood chemistry pulping and papermaking, Springer Series in Wood Science, First Edit., 1999, pp. 193-231.

H. Pakkanen, R. Matilainen, K. Lahti and K. Jaana, J. Chromatogr. A, 2007, 1139, 263-270.

H. Niemi, J. Lahti, H. Hatakka, S. Kärki, S. Rovio, M. Kallioinen, M. Mänttäri and M. Louhi-Kultanen, Chem. Eng. Technol., 2011, 34, 593-598.

S. Hellstén, J. Lahti, J. Heinonen, M. Kallioinen, M. Mänttäri and T. Sainio, Chem. Eng. Res. Des., 2013, 91, 2765-2774.

S. Hellstén, J. Heinonen and T. Sainio, Sep. Purif. Technol., 2013, 118, 234-241.

H. Kumar and R. Alén, Sep. Purif. Technol., 2015, 142, 293 298.

M. Mänttäri, J. Lahti, H. Hatakka and M. Kallioinen, J. Memb. Sci., 2015, 490, 84-91.

C. Chen, R. Alén, J. Lehto and H. Pakkanen, Nord. Pulp Pap. Res. J., 2016, 31, 532-540.

H. Kumar, Novel concepts on the recoery of by-products from alkaline pulping , PhdD thesis - University of Jyvaskyla, 2016. G. Kim, S. Park and B. Um, Ind. Crop. Prod., 2016, 89, 34-44. J. Heinonen and T. Sainio, Sep. Purif. Technol., 2019, 221, 349-362.

J. Heinonen and T. Sainio, Chem. Eng. Sci., 2019, 197, 87-97. J. Heinonen, Y. Zhao and B. Van der Bruggen, Sep. Purif. Technol., 2020, 240, 116642.

J. Hietala, A. Vuori, P. Johnsson, I. Pollari, W. Reutemann and H. Kieczka, ICIS Chem. Bus., 2017, 1, 1-12.

P. Pal and J. Nayak, Sep. Purif. Rev., 2017, 46, 44-61.

K. Ring, Chemical Economics Handbook - IHS Report - Formic Acid, 2016.

M. Rumayor, A. Dominguez-Ramos and A. Irabien, Appl. Sci., 2018, 8, 1-12.

M. Pérez-Fortes and E. Tzimas, Techno-economic and environmental evaluation of $\mathrm{CO} 2$ utilisation for fuel production. Synthesis of methanol and formic acid, European Commission Report, EUR 27629 EN, 2016.

S. Ha, R. Larsen and R. I. Masel, J. Power Sources, 2005, 144 28-34.

C. Fellay, P. J. Dyson and G. Laurenczy, Angew. Chemie Int. Ed., 2008, 47, 3966-3968.

F. Joó, ChemSusChem, 2008, 1, 805-808.

B. Saha and M. M. Sharma, React. Funct. Polym., 1996, 28, 263-278.

H. W. Gibson, Chem. Rev., 1969, 69, 673-692.

H. Cheung, R. Tanke and G. P. Torrence, Ullmann's Encycl. Ind. Chem., 2003, 8, 255-271. 

Players, Competitive Strategies and Forecasts - Research and Markets, Business Wire, 2017.

M. Jamshidian, E. A. Tehrany, M. Imran, M. Jacquot and S. Desobry, Compr. Rev. Food Sci. Food Saf., 2010, 9, 552-571. Lactic Acid Market Size, Share \& Trend Analysis Report By Raw Material (Corn, Sugarcane), By Application (Industrial, Food \& Beverages, Polylactic Acid), By Region, And Segment Forecasts, 2019-2025, Market Analysis Report - Grand View Research, 2019. J. Starr, Pr. Biotechnol, Curr Commod Prod, 1985, 3, 761776. R. Datta and M. Henry, J. Chem. Technol. Biotechnol., 2008, 83, 1163-1169.

O. M. Koivistoinen, J. Kuivanen, D. Barth, H. Turkia, J. P. Pitkänen, M. Penttilä and P. Richard, Microb. Cell Fact., 2013, 12, 1-16.

M. Kataoka, M. Sasaki, A. R. G. D. Hidalgo, M. Nakano and S. Shimizu, Biosci. Biotechnol. Biochem., 2001, 65, 2265-2270. Y. C. He, J. H. Xu, J. H. Su and L. Zhou, Appl. Biochem. Biotechnol., 2010, 160, 1428-1440.

G. Goor, J. Glenneberg and S. Jacobi, Ullmann's Encycl. Ind. Chem., 2000, 394-427.

J. Kubitschke, H. Lange and H. Strutz, in Ullmann's Encyclopedia of Industrial Chemistry, 2014, 1-18.

R.J. Yu \& E.J. Van Scott, US Patent, US4363815, 1982, 12.

T. Werpy and G. Petersen, Top Value Added Chemicals from Biomass, NREL Report DOE/GO-102004-1992, 2004.

M. Almond, D. Belton, P. N. Humphreys and A. P. Laws, Carbohydr. Res., 2016, 427, 48-54.

M. Almond, M. G. Suleiman, M. Hawkins, D. Winder, T. Robshaw, M. Waddoups, P. N. Humphreys and A. P. Laws, Carbohydr. Res., 2018, 455, 97-105.

M. J. Bailey, Appl. Microbiol. Biotechnol., 1986, 24, 493-498. S. H. Wang, J. L. McCarthy and J. F. Ferguson, Holzforschung, 1993, 47, 141-148.

L. R. Van Loon, M. A. Glaus, Experimental and Theoretical Studies on Alkaline Degradation of Cellulose and its Impact on the Sorption of Radionuclides, Research Report PSI-9807 -Paul Sherrer Institute, 1998.

M. A. Glaus, L. R. Van Loon, S. Achatz, A. Chodura and K. Fischer, Analytica Chimica Acta, 1999, 398, 111-122.

L. R. Van Loon, M. A. Glaus, S. Stallone and A. Laube, The degradation of cellulose: A problem for the safety of a radio active waste repository ? INIS Report INIS-CH--002,1997.

A. Toledano, A. García, I. Mondragon and J. Labidi, Sep. Purif. Technol., 2010, 71, 38-43.

L. Camprubi Gallet, Recovery and Purification of Hydroxy Carboxylic Acids from Soda Black Liquor, Master Thesis, Lappeenranta University of Technology, 2017.

H. Kumar and R. Alén, Ind. Eng. Chem. Res., 2014, 53, 94649470.

R. Alen and E. Sjostrom, Pap. ja Puu, 1980, 62, 328-330.

R. Alen and E. Sjostrom, Pap. ja Puu, 1980, 62, 469-471.

S. T. Yang, H. Huang, A. Tay, W. Qin, L. De Guzman and E. C. San Nicolas, Extractive Fermentation for the Production of Carboxylic Acids, in Bioprocessing for Value-Added Products from Renewable Resources, Elsevier B.V., 2007.

H. Huang, S. Ramaswamy, U. W. Tschirner and B. V Ramarao, Sep. Purif. Technol., 2008, 62, 1-21.

M. Al Manasrah, M. Kallioinen, $H$. Ilvesniemi and $M$. Mänttäri, Bioresour. Technol., 2012, 114, 375-381.

M. Mänttäri, A. Pihlajamäki and M. Nyström, Desalination, 2002, 149, 131-136.
O. Wallberg, A. S. Jönsson and R. Wimmerstedt, Desalination, 2003, 154, 187-199.

N. S. Kevlich, M. L. Shofner and S. Nair, Sep. Sci. Technol., 2017, 52, 1070-1094.

A. Keyoumu, R. Sjödahl, G. Henriksson, M. Ek, G. Gellerstedt and M. E. Lindström, Industrial Crops and Products, 2004, 20, 143-150.

I. Tanistra and M. Bodzek, Desalination, 1998, 115, 0-9.

N. S. Kevlich, M. L. Shofner and S. Nair, Sep. Sci. Technol., 2017, 52, 1070-1094.

J.W. Rowe, H.P. Gregor, US Patent US4584057, 1986.

M. Mänttäri, J. Lahti, H. Hatakka and M. Kallioinen, J. Memb. Sci., 2015, 490, 84-91.

S. Ramaswamy, H. J. Huang and B. V Ramarao, Separation and Purification Technologies in Biorefineries, John Wiley \& Sons, Ltd, 2013.

92 K. Tanaka and J. S. Fritz, J. Chromatogr. A, 1986, 361, 151160.

93 N. Rnas, J. Chromatogr. Libr., 1990, 46, 195-222.

S. Hellstén, Recovery of biomass-derived valuable compounds using chromatographic and membrane separations, PhdD thesis, University of Jyvaskyla, 2013.

C. L. Blanc, M. A. Theoleyre, F. Lutin, D. Pareau and M. Stambouli, Sep. Purif. Technol., 2015, 141, 105-112.

M. I. H. Helaleh, K. Tanaka, M. Mori, Q. Xu, H. Taoda, M. Y. Ding, W. Hu, K. Hasebe and P. R. Haddad, J. Chromatogr. A, 2003, 997, 139-144.

X. Ouyang, P. Zhang, X. Qiu, Y. Deng and P. Chen, Ind. Eng. Chem. Res., 2011, 50, 10792-10799.

98 M. Palm and G. Zacchi, Sep. Purif. Technol., 2004, 36, 191201.

99 J. Heinonen, Y. Zhao and B. Van der Bruggen, Sep. Purif. Technol., 2020, 240, 116-642.

100 X. Sun, Q. Wang, W. Zhao, H. Ma and K. Sakata, Sep. Purif. Technol., 2006, 49, 43-48.

101 W. Zhao, X. Sun, Q. Wang, H. Ma and Y. Teng, Biomass and Bioenergy, 2009, 33, 21-25.

102 H. J. Huang and S. R. Ramaswamy, in Separation and Purification Technologies in Biorefineries, John Wiley \& Sons, Ltd, First., 2013, pp. 3-36.

A. L. Tonkovich and E. Daymo, Handb. Therm. Sci. Eng., 2018, 34, 1535-1592.

104 A. Orjuela, A. Kolah, C. T. Lira and D. J. Miller, Ind. Eng. Chem. Res., 2011, 50, 9209-9220.

105 D. Painer, S. Lux and M. Siebenhofer, Sep. Sci. Technol., 2015, 50, 2930-2936.

106 E. Reyhanitash, T. Brouwer, S. R. A. Kersten, A. G. J. Van Der Ham and B. Schuur, Chem. Eng. Res. Des., 2018, 137, 510533.

107 L. M. J. Sprakel and B. Schuur, Sep. Purif. Technol., 2019, 211, 935-957.

108 C. S. López-Garzón and A. J. J. Straathof, Biotechnol. Adv., 2014, 32, 873-904.

109 L. M. J. Sprakel and B. Schuur, Sep. Purif. Technol., 2019, 211, 935-957.

110 A. Müller, Eckart; Berger, Rosemarie; Blass, ECkhart; Sluyts, Domien; Pfennig, Ullmann's Encycl. Ind. Chem., 2012, 309337.

J. Magnin, N. Papaiconomou and I. Billard, Sep. Purif. Technol., 2018, 196, 140-148. 